\title{
Article \\ Estradiol Protects against Noise-Induced Hearing Loss and Modulates Auditory Physiology in Female Mice
}

\author{
Benjamin Shuster ${ }^{1}$, Ryan Casserly ${ }^{1}$, Erika Lipford ${ }^{1}$, Rafal Olszewski ${ }^{2}$, Béatrice Milon ${ }^{1}$, Shaun Viechweg ${ }^{3}$, \\ Kanisa Davidson ${ }^{3}$, Jennifer Enoch ${ }^{3}$, Mark McMurray ${ }^{1}$, Mark A. Rutherford ${ }^{4}$, Kevin K. Ohlemiller ${ }^{4}$, \\ Michael Hoa ${ }^{2}$, Didier A. Depireux ${ }^{5}$ (D) Jessica A. Mong ${ }^{3}$ and Ronna Hertzano ${ }^{1,6,7, *}$
}

check for updates

Citation: Shuster, B.; Casserly, R.; Lipford, E.; Olszewski, R.; Milon, B.; Viechweg, S.; Davidson, K.; Enoch, J.; McMurray, M.; Rutherford, M.A.; et al. Estradiol Protects against Noise-Induced Hearing Loss and Modulates Auditory Physiology in Female Mice. Int. J. Mol. Sci. 2021, 22, 12208. https://doi.org/10.3390/ ijms222212208

Academic Editor: Hong-Yo Kang

Received: 8 October 2021

Accepted: 8 November 2021

Published: 11 November 2021

Publisher's Note: MDPI stays neutral with regard to jurisdictional claims in published maps and institutional affiliations.

Copyright: (c) 2021 by the authors Licensee MDPI, Basel, Switzerland. This article is an open access article distributed under the terms and conditions of the Creative Commons Attribution (CC BY) license (https:// creativecommons.org/licenses/by/ $4.0 /)$.
1 Department of Otorhinolaryngology-Head and Neck Surgery, University of Maryland School of Medicine, Baltimore, MD 21201, USA; benjamin.shuster@som.umaryland.edu (B.S.); ryan.casserly@gmail.com (R.C.); elipford@som.umaryland.edu (E.L.); bmilon@som.umaryland.edu (B.M.); mm2726@princeton.edu (M.M.)

2 Auditory Development and Restoration Program, National Institute on Deafness and Other Communication Disorders, NIH, Bethesda, MD 20892, USA; rafal.olszewski@nih.gov (R.O.); michael.hoa@nih.gov (M.H.)

3 Department of Pharmacology, University of Maryland School of Medicine, Baltimore, MD 21201, USA; stump86@gmail.com (S.V.); kdavidson@som.umaryland.edu (K.D.); jense674@gmail.com (J.E.); jmong@som.umaryland.edu (J.A.M.)

4 Department of Otolaryngology, Washington University School of Medicine, St. Louis, MO 63110, USA; rutherfordmark@wustl.edu (M.A.R.); kohlemiller@wustl.edu (K.K.O.)

5 Otolith Labs, Washington, DC 20036, USA; depireux@gmail.com

6 Department of Anatomy and Neurobiology, University of Maryland School of Medicine, Baltimore, MD 21201, USA

7 Institute for Genome Sciences, University of Maryland School of Medicine, Baltimore, MD 21201, USA

* Correspondence: rhertzano@som.umaryland.edu

\begin{abstract}
Recent studies have identified sex-differences in auditory physiology and in the susceptibility to noise-induced hearing loss (NIHL). We hypothesize that $17 \beta$-estradiol $\left(\mathrm{E}_{2}\right)$, a known modulator of auditory physiology, may underpin sex-differences in the response to noise trauma. Here, we gonadectomized B6CBAF1/J mice and used a combination of electrophysiological and histological techniques to study the effects of estrogen replacement on peripheral auditory physiology in the absence of noise exposure and on protection from NIHL. Functional analysis of auditory physiology in gonadectomized female mice revealed that $\mathrm{E}_{2}$-treatment modulated the peripheral response to sound in the absence of changes to the endocochlear potential compared to vehicle-treatment. $\mathrm{E}_{2}$ replacement in gonadectomized female mice protected against hearing loss following permanent threshold shift (PTS)- and temporary threshold shift (TTS)-inducing noise exposures. Histological analysis of the cochlear tissue revealed that $\mathrm{E}_{2}$-replacement mitigated outer hair cell loss and cochlear synaptopathy following noise exposure compared to vehicle-treatment. Lastly, using fluorescent in situ hybridization, we demonstrate co-localization of estrogen receptor- 2 with type-1C, high threshold spiral ganglion neurons, suggesting that the observed protection from cochlear synaptopathy may occur through $E_{2}$-mediated preservation of these neurons. Taken together, these data indicate the estrogen signaling pathways may be harnessed for the prevention and treatment of NIHL.
\end{abstract}

Keywords: noise-induced hearing loss; mouse model; estrogen; sex-differences; cochlear synaptopathy; inner ear; auditory physiology

\section{Introduction}

Disabling hearing loss afflicts nearly half a billion people worldwide. Noise-induced hearing loss (NIHL) - a form of acquired hearing loss — comprises a significant portion of this global burden, and its incidence is expected to increase [1,2]. Despite its widespread prevalence, there are currently no FDA-approved therapeutics for the prevention or treatment of NIHL, leaving amplification (hearing aids) and cochlear implantation as the sole treatment options $[3,4]$. 
The severity of NIHL presents as a continuum. Small increases in the intensity or duration of a noise exposure result in the progression from a less severe to a more severe subtype [5]. The least severe subtype of NIHL-referred to as a temporary threshold shift (TTS) - results in a temporary elevation of auditory thresholds without loss of, or permanent damage to, the mechanosensory cells of the cochlea-inner hair cells (IHCs) and outer hair cells (OHCs) - or their associated auditory nerve fibers (ANFs) arising from the spiral ganglion neurons (SGNs) [6]. A more severe subtype of NIHL called cochlear synaptopathy also produces a TTS but causes uncoupling and/or dysfunction of the synaptic connections between IHCs and high-threshold, low-spontaneous rate SGNs, which appear to correspond to type-1C SGNs [7-10]. In humans, cochlear synaptopathy is believed to underpin 'hidden hearing loss' (HHL), a functional impairment that includes difficulty understanding speech in noise $[9,11]$. Finally, the most severe subtype of NIHL results in a permanent elevation of auditory thresholds-or permanent threshold shift (PTS) - with attendant damage to, or loss of, IHCs and OHCs. Following octave-band noise exposures, this loss often occurs half an octave above the noise band and in the more vulnerable basal portions of the cochlea, where basal OHCs display an intrinsic vulnerability to damage caused by free radicals compared to more apical OHCs [6,12-14]

While NIHL afflicts both males and females, recent evidence suggests that females display increased resilience to NIHL compared to males, and that this resilience may be mediated by estrogen signaling [15-21]. Recent findings from our laboratory demonstrate that gonadally intact female mice are relatively protected from a PTS-inducing noise exposure in comparison to gonadally intact males [16]. Furthermore, estrogen receptor- $\beta$ (estrogen receptor 2 or ESR2) knockout (KO) mice of both sexes are more susceptible to TTS-inducing noise exposures than their wildtype littermate controls, while female ESR2 KO mice display early onset age-related hearing loss (ARHL) [22,23]. Both findings suggest that this protective effect may be, at least in part, mediated via ESR2-signaling.

The apparent protective effects of the estrogen signaling pathways offer a compelling avenue of investigation into their therapeutic potential. In the present study, we utilize a surgical gonadectomy model to characterize the effects of estrogen removal and replacement on peripheral auditory physiology in the absence of noise exposure. The surgical gonadectomy model eliminates circulating gonadal steroids including endogenous $E_{2}$ in mice of both sexes, as $E_{2}$ is generated in males by the aromatization of testosterone [24]. This model allows for control of circulating estrogen levels in vivo, and is a well-established model for the study of estrogenic modulation $[25,26]$. Next, using the same gonadectomy model, we characterize the effects of estrogen replacement in the context of either a PTS-inducing noise exposure (102.5 dB sound pressure level [SPL], 8-16 kHz, 2-h) or a less-severe, TTS-inducing noise exposure that causes cochlear synaptopathy ( $94 \mathrm{~dB} \mathrm{SPL}$, $8-16 \mathrm{kHz}, 2-\mathrm{h})$.

Our data indicate that estrogen replacement modulates peripheral auditory physiology in female mice in the absence of noise exposure. We also demonstrate that estrogen replacement in gonadectomized female mice reduces auditory threshold shifts following both a PTS-inducing and TTS-inducing noise exposure. Furthermore, we show that surgical gonadectomy increases, and estrogen replacement decreases, OHC loss and cochlear synaptopathy. Finally, using fluorescent in situ hybridization, we demonstrate colocalization of Esr 2 with type-1C SGNS, suggestive of an $E_{2}$-mediated protective effect against cochlear synaptopathy through preservation of type-1C SGNs. Taken together, these data indicate the estrogen signaling pathways may show promise for the prevention and treatment of NIHL.

\section{Results}

\subsection{E $E_{2}$-Replacement Decreases Auditory Thresholds and Increases Wave-1 Amplitude}

We quantified auditory brainstem responses (ABRs), which reflect synchronous neural activity along the ascending auditory pathway [27], to evaluate the effects of $E_{2}$-replacement on peripheral auditory physiology in the absence of noise exposure. Eight-week-old 
female mice underwent surgical gonadectomy and recovered for a period of 1-week. At 9-weeks of age, all mice were administered a vehicle control, and auditory thresholds and wave- 1 amplitudes were quantified via ABR measurements. At 10-weeks of age, the same cohort was acutely administered $\mathrm{E}_{2}$. The day following the final subcutaneous injection of $\mathrm{E}_{2}$, auditory thresholds and wave- 1 amplitudes were quantified via $A B R$ measurements (Figure 1A).

A

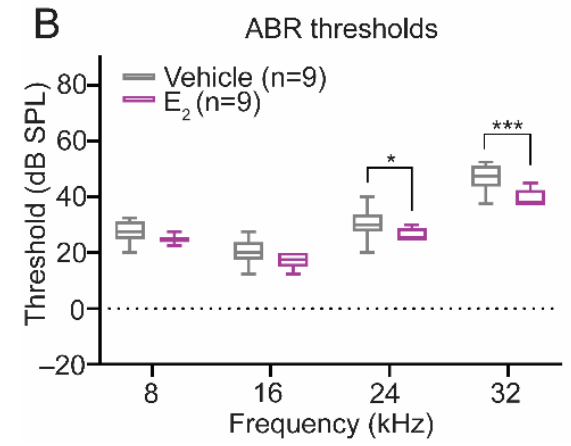

C

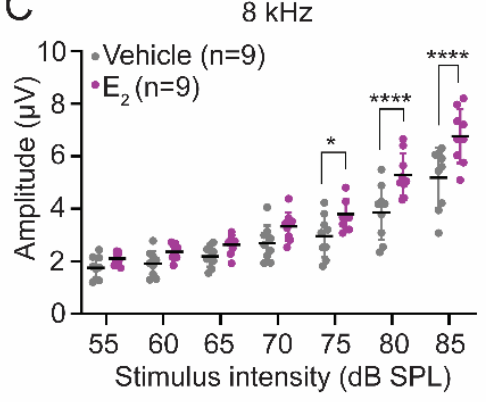

E

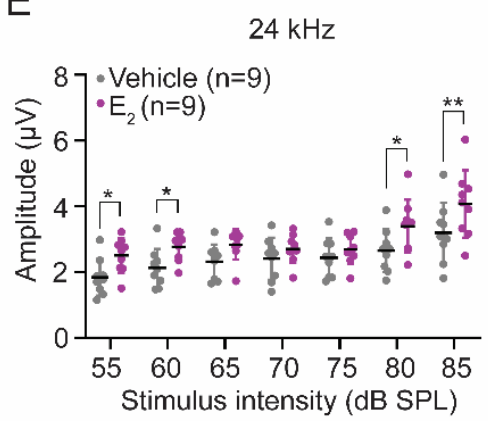

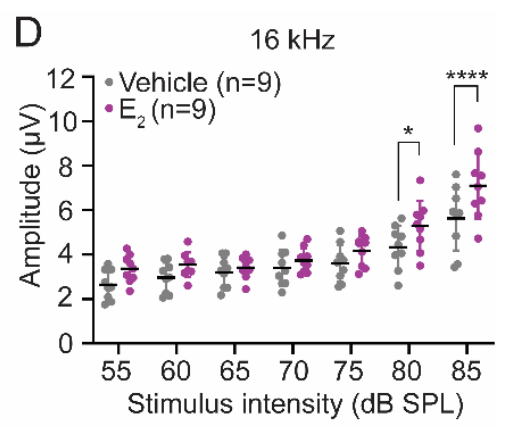

$\mathrm{F}$

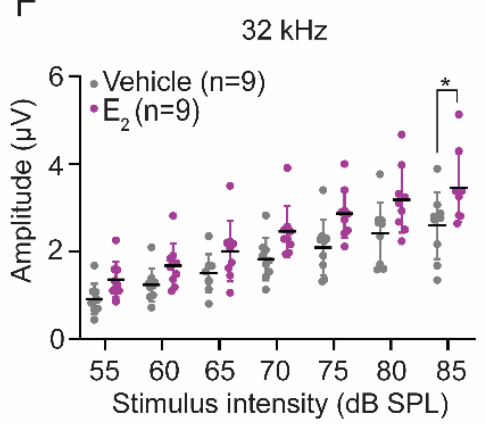

Figure 1. $E_{2}$-replacement in gonadectomized female mice modulates auditory brainstem response (ABR) thresholds and wave-1 amplitudes. (A) Schematic of the within-animal experimental design. Female mice were gonadectomized at 8-weeks of age. Mice received 3 daily subcutaneous injections of vehicle 1-week post-gonadectomy and 3 daily subcutaneous injections of $E_{2}(300 \mu \mathrm{g} / \mathrm{kg})$ 2-weeks post-gonadectomy. (B) Following $E_{2}$-replacement, ABR thresholds improved at $24 \mathrm{kHz}(p=0.0416)$ and $32 \mathrm{kHz}(p=0.0003)$. (C-F) $\mathrm{E}_{2}$-replacement increases suprathreshold ABR wave-1 amplitudes at (C) $8 \mathrm{kHz}$ (75 dB sound pressure level [SPL]: $p=0.0358 ; 80 \mathrm{~dB}$ SPL: $p<0.0001 ; 85 \mathrm{~dB}$ SPL: $p<0.0001)$; (D) $16 \mathrm{kHz}(80 \mathrm{~dB}$ SPL: $p=0.0128$; $85 \mathrm{~dB}$ SPL: $p<0.0001)$; (E) $24 \mathrm{kHz}$ (55 dB SPL: $p=0.0345 ; 60 \mathrm{~dB}$ SPL: $p=0.0438 ; 80 \mathrm{~dB}$ SPL: $p=0.0134$; $85 \mathrm{~dB}$ SPL: $p=0.0023)$; and (F) $32 \mathrm{kHz}$ (85 dB SPL: $p=0.0325)$. ABR thresholds and wave-1 amplitudes are compared before and after $E_{2}$-replacement in the same animals using a RM 2-way ANOVA followed by Sidak's multiple comparison test. $n=$ number of mice; ABR thresholds: minimum value, 1st quartile, median, 3rd quartile, maximum value; Wave- 1 amplitudes: mean $\pm \mathrm{SD} ;{ }^{*} p<0.05,{ }^{* *} p<0.01,{ }^{* * *} p<0.001,{ }^{* * *} p<0.0001$.

Auditory thresholds and wave- 1 amplitudes were compared before and after $E_{2}-$ replacement within the same animals. Following $E_{2}$-replacement, $A B R$ thresholds improved at $24 \mathrm{kHz}(p=0.0416)$ and $32 \mathrm{kHz}(p=0.0003)$ (Figure 1B). Suprathreshold wave1 amplitudes-a measure of the synchronous neural activity at the level of the spiral ganglion-were compared before and after $\mathrm{E}_{2}$-replacement in each animal. We observed statistically significant increases in the wave- 1 amplitudes at each frequency tested, particularly at the higher stimulus intensities (Figure 1C-F). Using an additional cohort, we quantified the number of IHC synapses in $\mathrm{E}_{2}$-treated and vehicle-treated female mice to determine if the observed improvements in auditory thresholds and increase in wave-1 amplitudes could be the result of changes to the number of paired IHC-ANF synapses. This cohort utilized a between animal design (Figure 2A). Mice in the vehicle-treated condition received additional subcutaneous vehicle injections during the second week of data collection, while mice in the $\mathrm{E}_{2}$-treated condition received subcutaneous injections of $\mathrm{E}_{2}$. Like the original cohort, $E_{2}$-treated mice displayed significantly larger wave-1 amplitudes 
at all frequencies examined (data not shown). Despite the increase in wave-1 amplitudes observed in the $\mathrm{E}_{2}$-treated mice, there was no significant effect of treatment on the number of paired synapses per IHC at any frequency tested (Figure 2B), indicating that the observed increase in wave- 1 amplitude following $\mathrm{E}_{2}$-replacement cannot be attributed to an increase in the number of paired synapses.

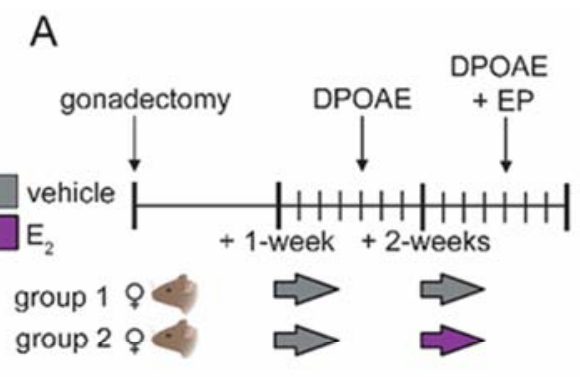

D

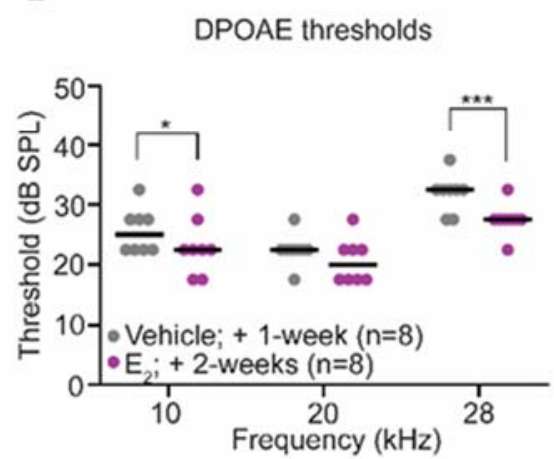

B

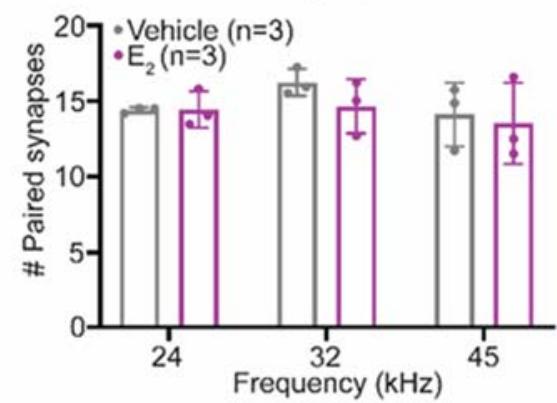

E

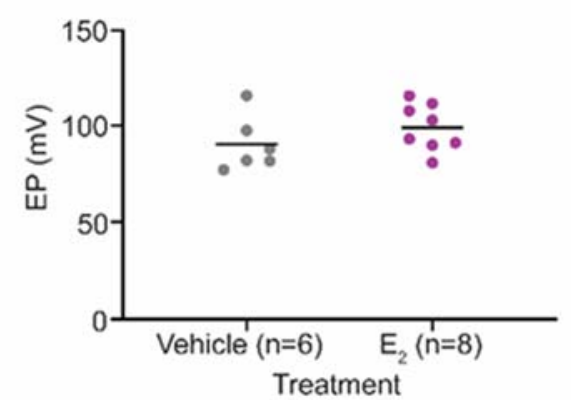

C

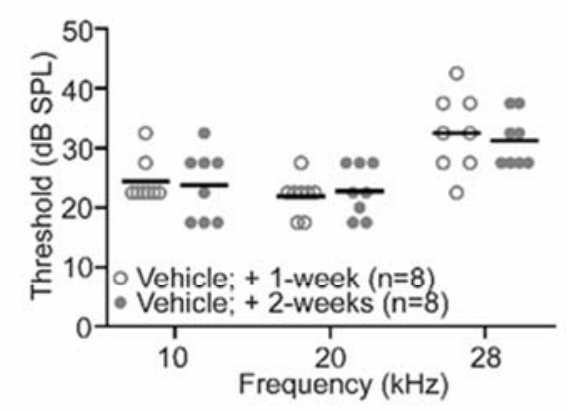

$\mathrm{F}$

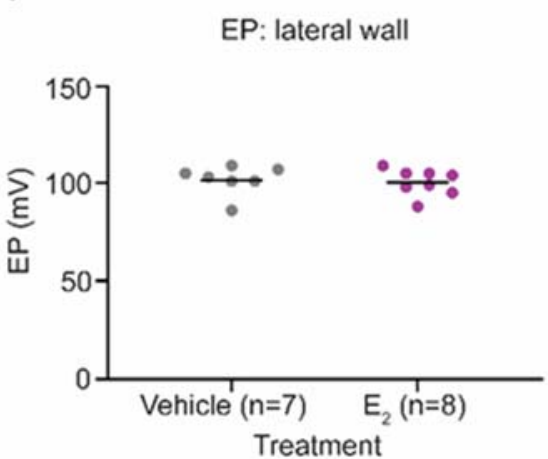

Figure 2. $E_{2}$-replacement in gonadectomized female mice improves distortion product otoacoustic emission (DPOAE) thresholds but does not alter the number of paired inner hair cell (IHC) synapses or the endocochlear potential. (A) Schematic of the experimental design. Both cohorts of mice received 3 daily subcutaneous injections of vehicle 1-week post-gonadectomy. Two-weeks post-gonadectomy, one cohort received 3 daily subcutaneous injections of vehicle, while the other cohort received 3 daily subcutaneous injections of $E_{2}(300 \mu \mathrm{g} / \mathrm{kg})$. (B) Histological analysis of cochlear tissue collected from vehicle-treated and $\mathrm{E}_{2}$-treated mice demonstrated no differences in the number of paired IHC-auditory nerve fiber (ANF) synapses. (C) Analysis of DPOAE thresholds in the cohort treated with vehicle during both weeks of data collection revealed no changes. (D) Following $\mathrm{E}_{2}$-replacement, gonadectomized female mice displayed improved DPOAE thresholds at $10 \mathrm{kHz}(p=0.0216)$ and $28 \mathrm{kHz}(p=0.0001)$. (E,F) The endocochlear potential measured via a round window approach (E) and via a lateral wall approach $(\mathbf{F})$ is not changed by $E_{2}$-replacement. DPOAE thresholds were compared within groups using a RM 2-way ANOVA followed by Sidak's multiple comparison test. Paired synapses were compared using a 2-way ANOVA followed by Sidak's multiple comparisons test. Endocochlear potentials were compared using a student's $t$-test. $n=$ number of mice; Paired synapses: mean \pm SD; DPOAE thresholds and EP measurements: bars display the mean;

${ }^{*} p<0.05,{ }^{* * *} p<0.001$.

\subsection{E $E_{2}$-Replacement Decreases Distortion Product Otoacoustic Emission Thresholds}

Within the cochlea, OHCs act as signal amplifiers and contribute to ABRs through their effects on IHCs [28]. Distortion product otoacoustic emissions (DPOAEs) are sounds emitted specifically by $\mathrm{OHCs}$ as a result of their electromotive properties [29], and can be used to assess OHC function [30]. To investigate whether the improved auditory thresholds and increase in wave- 1 amplitudes may be the result of an increase in signal amplification by OHCs, we quantified DPOAE thresholds in vehicle-treated and $\mathrm{E}_{2}$-treated female mice (Figure 2A). 
We observed no changes in DPOAE thresholds in mice that received vehicle injections during both weeks of data collection (Figure 2C). In contrast, in the cohort that received $\mathrm{E}_{2}$-replacement during the second week of data collection, within-group analysis revealed improved DPOAE thresholds following $\mathrm{E}_{2}$-replacement at $10 \mathrm{kHz}(p=0.0216)$ and $28 \mathrm{kHz}(p=0.0001)$, suggesting that $\mathrm{E}_{2}$-replacement modulates $\mathrm{OHC}$ physiology in gonadectomized female mice in the absence of noise exposure (Figure 2D).

\subsection{E-Replacementon Does Not Affect the Endocochlear Potential}

Another possible explanation for the observed electrophysiological changes, including the improvement in DPOAE thresholds, is that $\mathrm{E}_{2}$-replacement modulates the endocochlear potential (EP). The apical surfaces of the mechanosensory cells in the inner ear are bathed in an extracellular fluid called endolymph, normally characterized by a high potassium $\left(\mathrm{K}^{+}\right)$concentration and a positive electric potential (in mice) of about $100 \mathrm{mV}$ [31,32]. This positive EP is critical for cochlear hair cell mechanotransduction, and changes to the EP can alter ABR thresholds [33-35]. The EP was measured in 10-week-old vehicle-treated and $\mathrm{E}_{2}$-treated female mice (Figure 2A). This experiment was performed two ways in different cohorts, first using a round window approach (Figure 2E) and second using a lateral wall approach (Figure 2F) to verify consistency in EP measurements between the two experimental techniques. We observed no differences between the vehicle-treated and $\mathrm{E}_{2}$-treated animals using either experimental approach, indicating $\mathrm{E}_{2}$-replacement does not affect the $\mathrm{EP}$, and that the observed electrophysiological changes following $\mathrm{E}_{2}$-replacement are not the result of changes to the EP.

\subsection{Gonadectomy Eliminates Sex Differences in the Response to PTS-Inducing Noise}

Following the evaluation of the effects of $E_{2}$-replacement on peripheral auditory physiology in the absence of noise exposure, we next evaluated the potential protective effects of $\mathrm{E}_{2}$-replacement against NIHL. In a previous report, we demonstrated that gonadally intact female B6CBAF1/J mice displayed relative protection from PTS-inducing noise (101 dB SPL, 8-16 kHz, 2-h) in comparison to gonadally intact males [16]. Here, we examined whether the previously documented protection from PTS-inducing noise in female mice is a result of gonadal $E_{2}$. Eight-week-old male and female B6CBAF1/J mice were gonadectomized and implanted with a subcutaneous osmotic pump delivering either $\mathrm{E}_{2}$ or a vehicle control (Figure $3 \mathrm{~A}$ ). ABR measurements were used to compare hearing thresholds at 3 timepoints: (1) following gonadectomy and 1-week before noise exposure (baseline); (2) 24-h post-exposure to quantify the compound threshold shift (CTS) [36]; and (3) 2-weeks post-exposure to quantify the PTS (Figure 3A).

At baseline, there were no differences in auditory thresholds between vehicle-treated males and females at any frequency tested (Figure 3B). Twenty-four hours after the PTSinducing exposure, gonadectomized vehicle-treated male and female mice displayed no differences in the magnitude of the CTS across all frequencies tested (Figure 3C). Similarly, ABR measurements collected 2-weeks post-exposure in gonadectomized vehicle-treated male and female mice displayed no differences in the magnitude of the PTS across all frequencies tested (Figure 3D). These results demonstrate that the sex-dependent protective effect previously reported is abolished in the absence of circulating gonadal steroids.

\subsection{E $E_{2}$-Replacement Protects against PTS-Inducing Noise in Female Mice}

Using the same experimental timeline, in another cohort of mice we then investigated whether $\mathrm{E}_{2}$-replacement re-establishes the sex-dependent protective effect [16]. At baseline, $\mathrm{E}_{2}$-treated males and females displayed similar ABR thresholds at all frequencies tested. Additionally, there were no differences in baseline thresholds after $\mathrm{E}_{2}$-treatment in male or female mice (Figure 3B). 

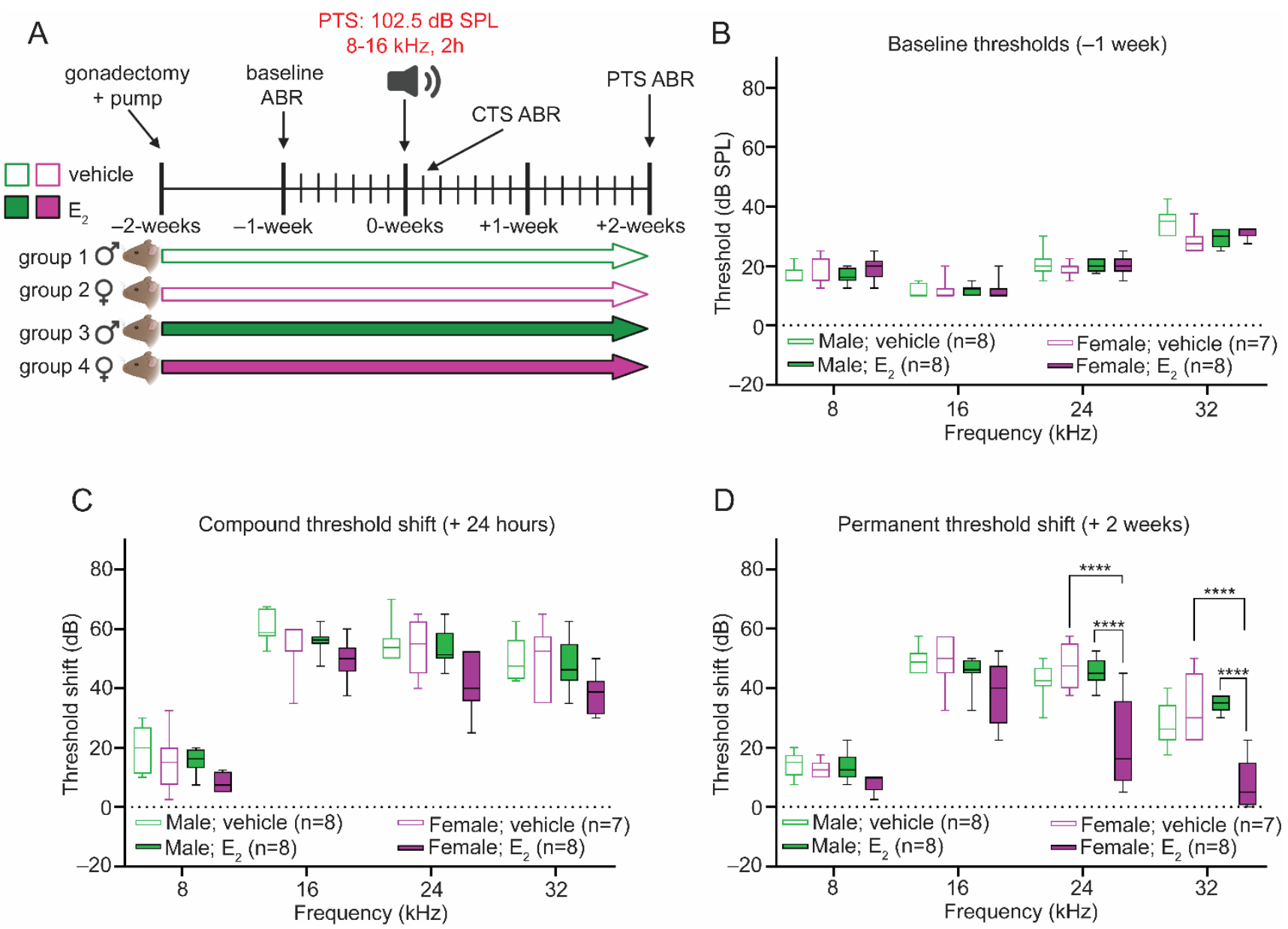

Figure 3. $E_{2}$-replacement in gonadectomized female mice protects against hearing loss following a PTS-inducing noise exposure. (A) Experimental schematic. Male and female mice were gonadectomized at 8-weeks of age and implanted with an osmotic pump to deliver vehicle or $E_{2}(1 \mu \mathrm{g} /$ day $)$ for the duration of the study. Animals were exposed to a permanent threshold shift (PTS)-inducing noise (102.5 dB SPL, 8-16 kHz, 2-h) at 10-weeks of age. Auditory thresholds were quantified via ABR measurements 1-week pre-exposure (baseline), 24-h post-exposure (compound threshold shift or CTS), and 2-weeks post-exposure (permanent threshold shift or PTS). (B) Vehicle-treated and $\mathrm{E}_{2}$-treated male and female mice display similar baseline ABR thresholds. (C) Twenty-four hours post-exposure, vehicle-treated and $\mathrm{E}_{2}$-treated male and female mice display a CTS of a similar magnitude at all frequencies examined. (D) Two-weeks post-exposure, E2-treated female mice display a reduced PTS compared to $\mathrm{E}_{2}$-treated males at $24 \mathrm{kHz}(p<0.0001)$ and $32 \mathrm{kHz}(p<0.0001)$ and compared to vehicle-treated females at $24 \mathrm{kHz}(p<0.0001)$ and $32 \mathrm{kHz}(p<0.0001)$. Vehicle-treated male and female mice display a PTS of a similar magnitude across all frequencies tested. Similarly, vehicle-treated and $\mathrm{E}_{2}$-treated males displayed no differences in the magnitude of the PTS across all frequencies tested. ABR thresholds were compared using a 3-way ANOVA followed by Tukey's post-hoc test. $n=$ number of mice; ABR thresholds: minimum value, 1st quartile, median, 3rd quartile, maximum value; ${ }^{* * * *} p<0.0001$.

Analysis of the CTS 24-h post-exposure revealed a significant main effect of treatment $\left(F_{1,108}=17.15\right)$ and biological sex $\left(F_{1,108}=21.04\right)$, although a comparison between $E_{2}$-treated females and either $\mathrm{E}_{2}$-treated males or vehicle-treated females did not reveal statistically significant reductions in the CTS at any frequency tested. Vehicle-treated and $\mathrm{E}_{2}$-treated males displayed a CTS of a similar magnitude at all frequencies tested (Figure 3C). Analysis of the PTS 2-weeks post-exposure revealed that $\mathrm{E}_{2}$-treated females displayed a robust reduction in the magnitude of the PTS compared to both vehicle-treated females and $\mathrm{E}_{2}$-treated males at $24 \mathrm{kHz}(p<0.0001)$ and $32 \mathrm{kHz}(p<0.0001)$ (Figure 3D). The observed protective effect of $E_{2}$-replacement was confined to female mice, as $E_{2}$-treated and vehicletreated males displayed a similar PTS at all frequencies tested (Figure 3D). 


\subsection{E2-Replacement Reduces OHC Loss following a PTS-Inducing Noise Exposure}

To validate our physiologic data and to obtain tissue for histological analyses, we utilized an additional cohort where $\mathrm{E}_{2}$-replacement was administered using subcutaneous injections of $17 \beta$-estradiol-3-benzoate (from here on referred to as $\mathrm{E}_{2}$ ) (Figure $4 \mathrm{~A}$ ). This cohort used female mice only because we observed $\mathrm{E}_{2}$-mediated protection from PTSinducing noise exposure in female but not male mice. Cochleae were collected 1-week following the PTS-inducing noise exposure, since we determined in previous studies that permanent threshold shifts did not change between the 1-week and 2-week post-exposure ABRs [16]. In the areas corresponding to the frequency-specific PTS-16 kHz, $24 \mathrm{kHz}$, and $32 \mathrm{kHz}$ - there was no OHC loss and therefore no difference in OHC survival between the experimental conditions. However, in the basal portion of the cochlea corresponding to frequencies between $45.2 \mathrm{kHz}$ and $55.0 \mathrm{kHz}, \mathrm{E}_{2}$-treated mice displayed significantly improved OHC survival $(p<0.0001)$, consistent with an $\mathrm{E}_{2}$-induced otoprotective effect (Figure 4B). The pattern of $\mathrm{OHC}$ loss following this noise exposure paradigm is consistent with our previously published data, showing that a similar noise exposure in this strain of mice results in an extensive loss of OHCs in the basal part of the cochlea, whereas the frequency-specific hearing loss is associated with $\mathrm{OHC}$ dysfunction but not with an immediate OHC loss [16]. Paired IHC synapses were also quantified from the same cohort of animals 1-week post-exposure. There were no observed differences in paired synapse numbers between the $\mathrm{E}_{2}$-treated and vehicle-treated female mice at any frequency examined (Figure 4C).

\subsection{Protective Effect of $E_{2}$-Replacement on Hearing Thresholds following TTS-Inducing Noise}

While $\mathrm{E}_{2}$-replacement ameliorated hearing loss and improved $\mathrm{OHC}$ survival in female mice following a PTS-inducing noise exposure, vehicle-treated and $\mathrm{E}_{2}$-treated female mice displayed a similar degree of synapse loss (compare Figures $2 B$ and $4 C$ ). The sound energy required to induce a PTS exceeds the sound energy required to induce cochlear synaptopathy in CBA/CaJ mice [37], and permanent shifts in auditory thresholds are concomitant with synaptic uncoupling and dysfunction to a degree that may have exceeded the therapeutic capacity of $E_{2}$-replacement. Thus, to evaluate the effect of $E_{2}$-replacement on protection from cochlear synaptopathy, we utilized a less-intense, TTS-inducing noise exposure (94 dB SPL, 8-16 kHz, 2-h). Given that the protective effect of $E_{2}$ was confined to female mice in the PTS-inducing experiments, our investigation of $\mathrm{E}_{2}$ 's protective effects from here on utilized female mice only.

Eight-week-old female B6CBAF1/J mice underwent surgical gonadectomy and subsequently received vehicle treatment or $\mathrm{E}_{2}$-replacement (Figure 5A). At baseline, there were no differences in auditory thresholds between the vehicle-treated and $\mathrm{E}_{2}$-treated mice (Figure 5B). Twenty-four hours following the noise exposure, analysis of the CTS revealed that $\mathrm{E}_{2}$-treated mice displayed a significantly reduced CTS at $16 \mathrm{kHz}(p=0.0266), 24 \mathrm{kHz}$ $(p=0.0001)$, and $32 \mathrm{kHz}(p=0.0001)$, compared to the vehicle-treated mice (Figure 5C). Consistent with this noise exposure producing a TTS, auditory thresholds returned to baseline in both experimental conditions, and comparison of the 1-week threshold shifts between treatment groups revealed no differences (Figure 5D). 

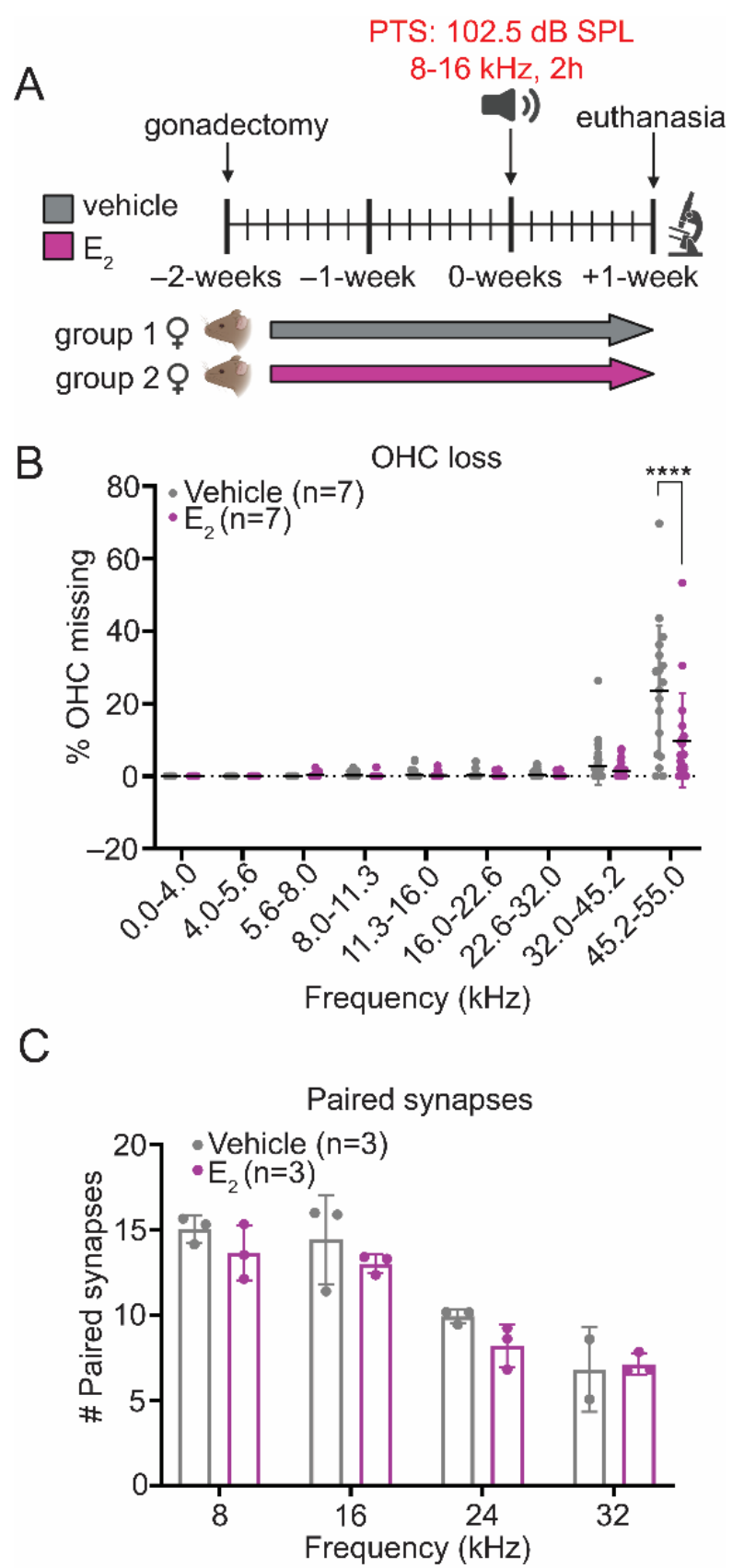

Figure 4. $\mathrm{E}_{2}$-replacement in female mice increases outer hair cell $(\mathrm{OHC})$ survival in the base of the cochlea following a PTS-inducing noise exposure. (A) Experimental schematic. Female mice were gonadectomized at 8-weeks of age and treated with vehicle or $E_{2}(150 \mu \mathrm{g} / \mathrm{kg})$ beginning 2-days after the gonadectomy for the remaining duration of the study. Animals were euthanized for tissue collection 1-week post-exposure. (B) $\mathrm{E}_{2}$-replacement in female mice increases OHC survival in the base of the cochlea $(45.2-55.0 \mathrm{kHz}) 1$-week following a PTS-inducing noise exposure $(p<0.0001)$. (C) $\mathrm{E}_{2}$-replacement in female mice does not reduce the loss of paired IHC-ANF synapses 1-week following a PTS-inducing noise exposure. OHC survival and paired synapse number were compared between groups using a 2-way ANOVA followed by Sidak's multiple comparison test. $n=$ number of ears; plots: mean $\pm \mathrm{SD} ;{ }^{* * *} p<0.0001$. 

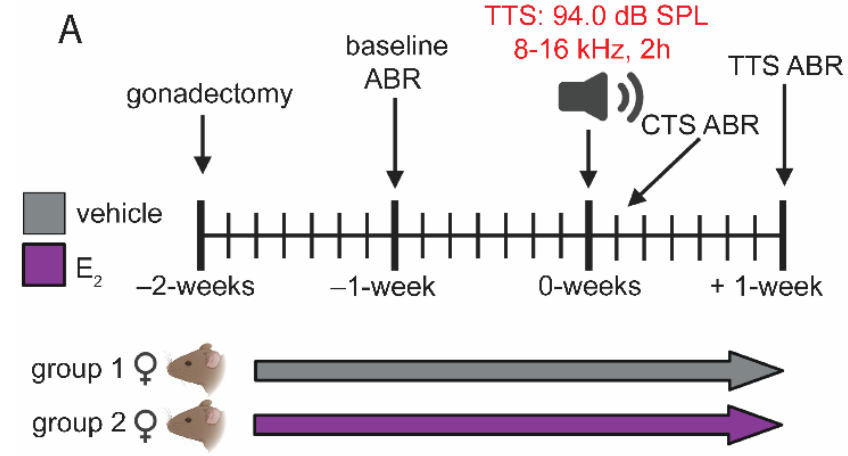

C Compound threshold shift (+ 24 hours)

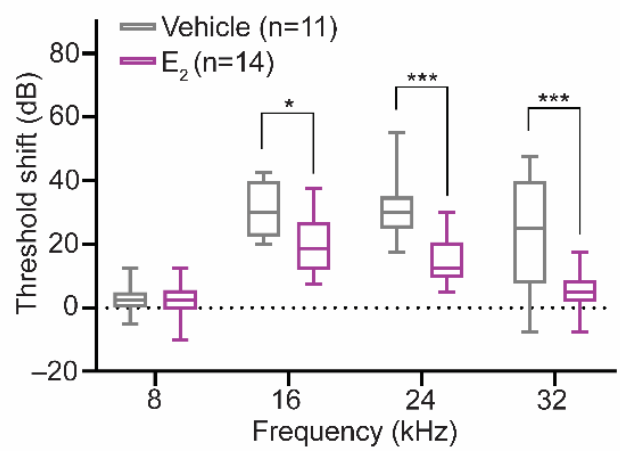

B

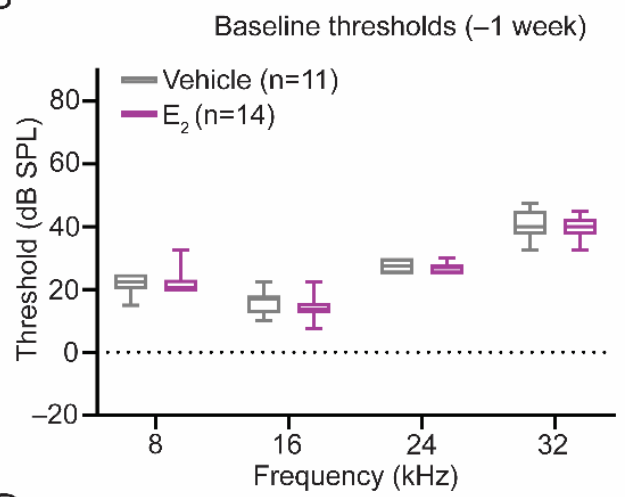

D

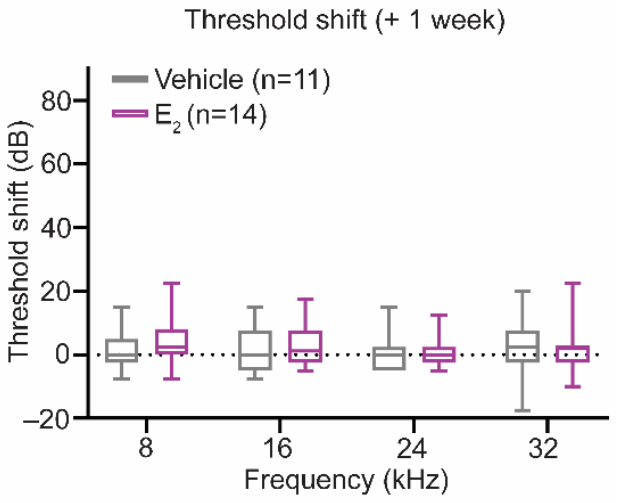

Figure 5. $\mathrm{E}_{2}$-replacement in gonadectomized female mice reduces the CTS after a temporary threshold shift (TTS)-inducing noise exposure. (A) Experimental schematic. Female mice were gonadectomized at 8-weeks of age and treated with vehicle or $E_{2}(150 \mu \mathrm{g} / \mathrm{kg})$ beginning 2-days after the gonadectomy for the remaining duration of the study. Animals were exposed to a TTS-inducing noise ( $94 \mathrm{~dB}$ SPL, $8-16 \mathrm{kHz}, 2-\mathrm{h}$ ) at 10-weeks of age. Auditory thresholds were quantified via ABR measurements 1-week pre-exposure (baseline), 24-h post-exposure (CTS), and 1-week post-exposure. (B) At baseline, vehicle-treated and $E_{2}$-treated mice display no differences in ABR thresholds at any frequency tested. $(C) E_{2}$-treated female mice display a reduced CTS at $16 \mathrm{kHz}(p=0.0266), 24 \mathrm{kHz}(p=0.0001)$, and $32 \mathrm{kHz}(p=0.0001)$. (D) Despite the differences in the magnitude of the CTS, there are no differences in ABR thresholds 1-week post-exposure between the $E_{2}$-treated and vehicle-treated female at any frequency tested. ABR thresholds were compared using a 2-way ANOVA followed by Tukey's post-hoc test. $n=$ number of mice; ABR thresholds: minimum value, 1st quartile, median, 3rd quartile, maximum value; ${ }^{*} p<0.05,{ }^{* * *} p<0.001$.

Next, we evaluated the effect of $E_{2}$-replacement on ABR wave-1 amplitudes. A reduction in wave- 1 amplitude in TTS-inducing noise exposure paradigms is used to indirectly assess the presence of cochlear synaptopathy, although recent studies demonstrate the potential for a reduction in wave- 1 amplitude also in the absence of cochlear synaptopathy [17].

Wave-1 amplitudes were extracted from ABR tracings at baseline and 1-week postexposure. Analysis of baseline amplitudes revealed a significant main effect of treatment at each frequency tested, indicating $\mathrm{E}_{2}$-treated mice displayed significantly larger $\mathrm{ABR}$ wave-1 amplitudes overall compared to vehicle-treated mice (Figure 6A-D, Table 1). One-week post-exposure, wave- 1 amplitudes decreased in both groups of mice but remained larger overall in the $\mathrm{E}_{2}$-treated mice, as a comparison of wave- 1 amplitudes revealed a significant main effect of treatment at all frequencies tested (Figure 6A-D). The maintenance of larger wave- 1 amplitudes in the $\mathrm{E}_{2}$-treated mice suggests increased synchronous neural activity at the level of the spiral ganglion and potentially an $\mathrm{E}_{2}$-mediated protection from cochlear synaptopathy. We therefore quantified the number of paired synapses in vehicle-treated and $E_{2}$-treated mice 1-week post-exposure. Compared to a group of sham exposed mice, $\mathrm{E}_{2}$-treated mice displayed the same number of synapses at each frequency examined. In 
contrast, compared to the $\mathrm{E}_{2}$-treated mice, vehicle-treated mice displayed an average loss of 5.9 paired synapses at $24 \mathrm{kHz}(p<0.0001)$, suggestive of a frequency-dependent, $\mathrm{E}_{2}$ mediated protective effect from cochlear synaptopathy following a TTS-inducing noise exposure (Figure 7A-D).

A

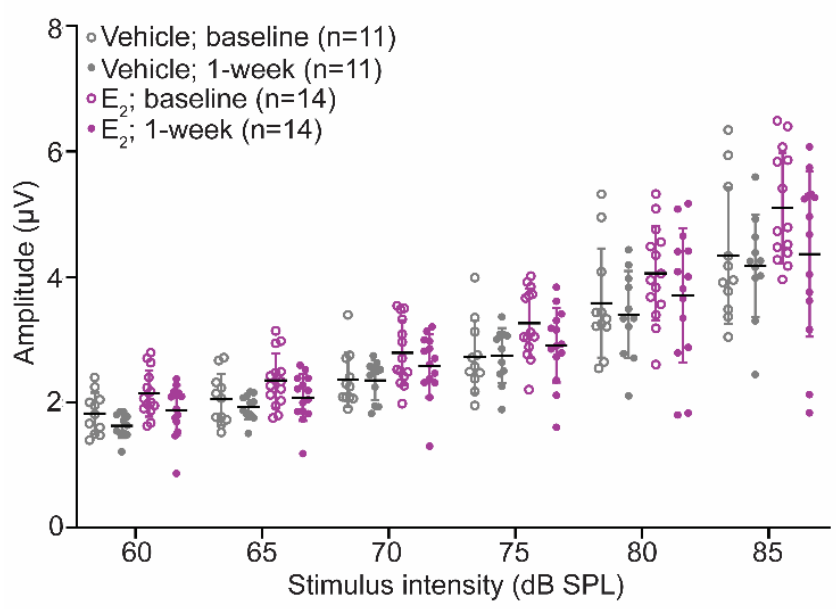

C

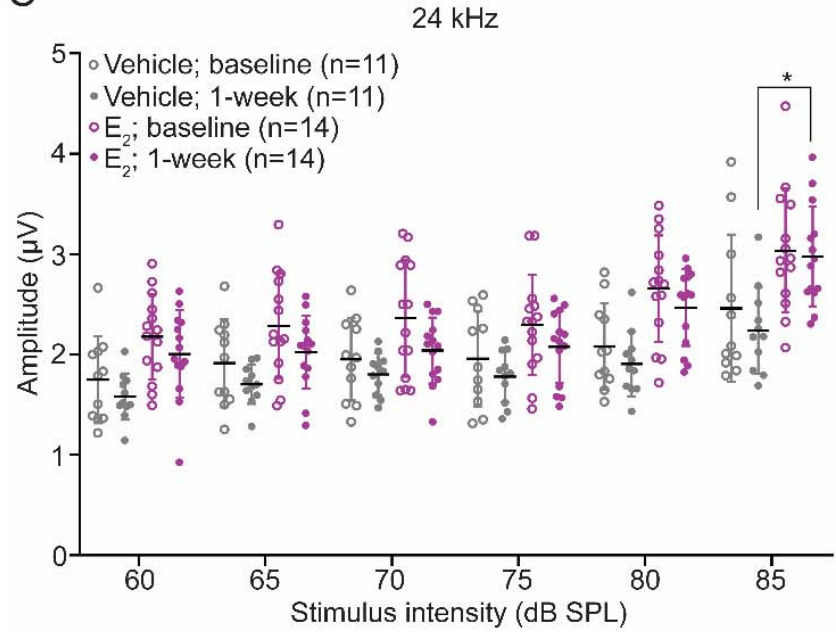

B
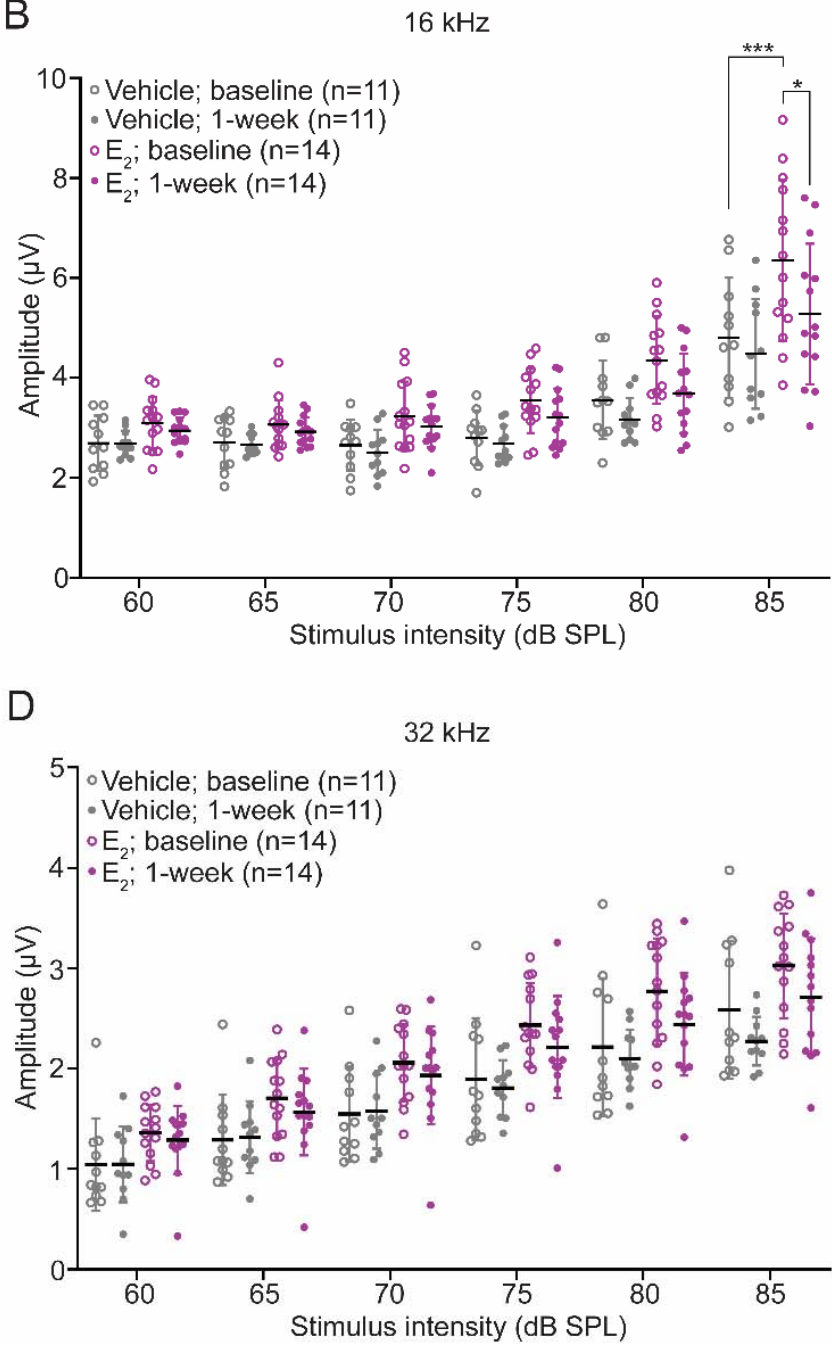

Figure 6. $\mathrm{E}_{2}$-replacement in gonadectomized female mice increases wave-1 amplitudes before and after a TTS-inducing noise exposure. (A-D): Wave-1 amplitudes in vehicle-treated and $\mathrm{E}_{2}$-treated mice at baseline and 1-week post-exposure. Female mice were gonadectomized at 8-weeks of age and treated with vehicle or $E_{2}(150 \mu \mathrm{g} / \mathrm{kg})$ beginning 2-days after the gonadectomy for the remaining duration of the study. Animals were exposed to a TTS-inducing noise $(94 \mathrm{~dB} \mathrm{SPL}, 8-16 \mathrm{kHz}$, 2-h) at 10-weeks of age. Wave-1 amplitudes were quantified via ABR measurements 1-week pre-exposure (baseline) and 1-week post-exposure. (B) At baseline, $E_{2}$-treated mice display larger wave-1 amplitudes at $16 \mathrm{kHz}$ : $85 \mathrm{~dB}$ SPL ( $\left.p=0.0001\right)$. (C) One-week post-exposure $\mathrm{E}_{2}$-treated female mice display larger wave-1 amplitudes at $24 \mathrm{kHz}$ : $85 \mathrm{~dB}$ SPL $(p=0.0111)$. Wave-1 amplitudes were compared using a 3-way ANOVA followed by Tukey's post hoc test. $n=$ number of mice; Wave-1 amplitude: mean $\pm \mathrm{SD} ;{ }^{*} p<0.05,{ }^{* * *} p<0.001$. 

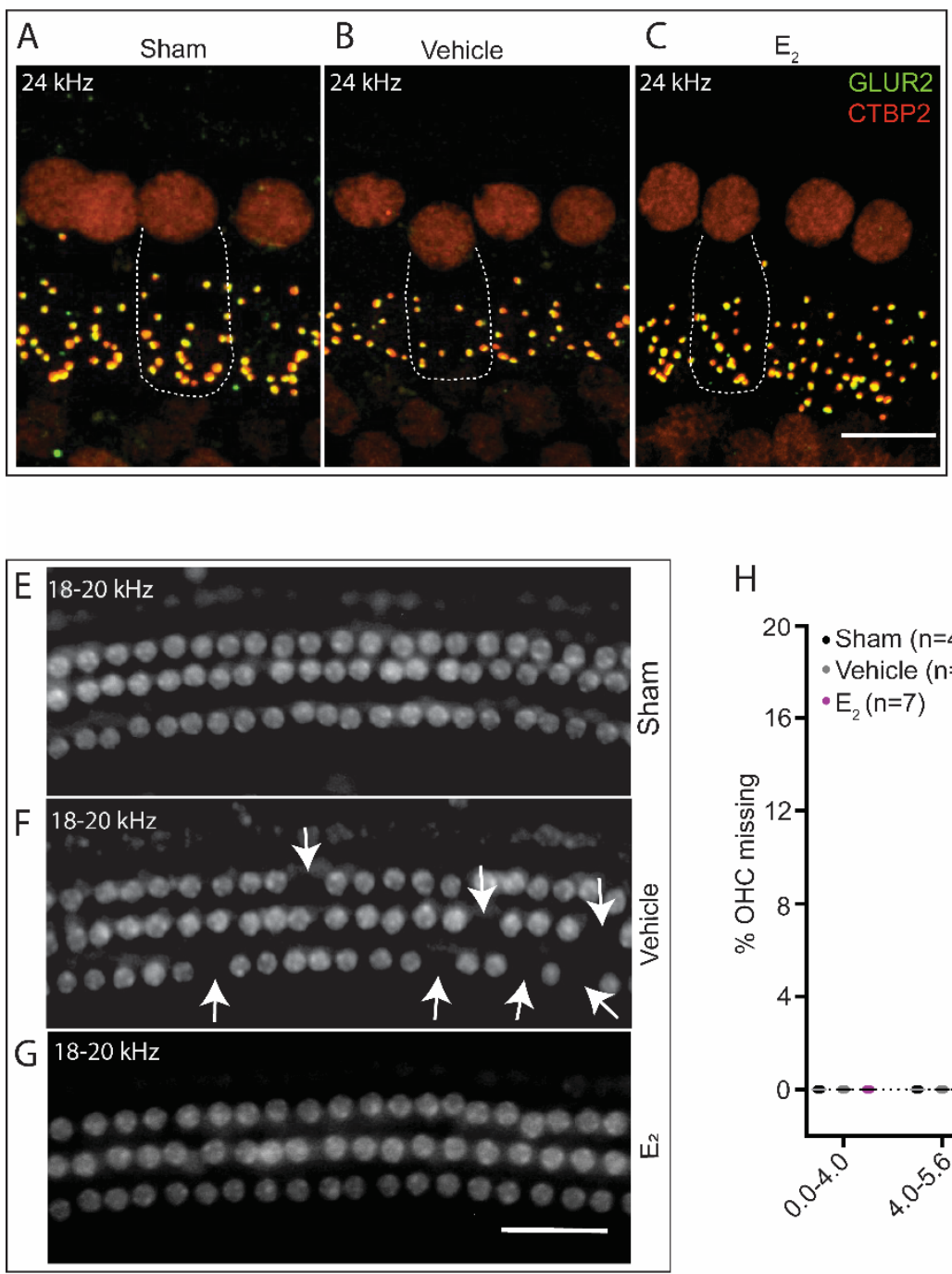

D

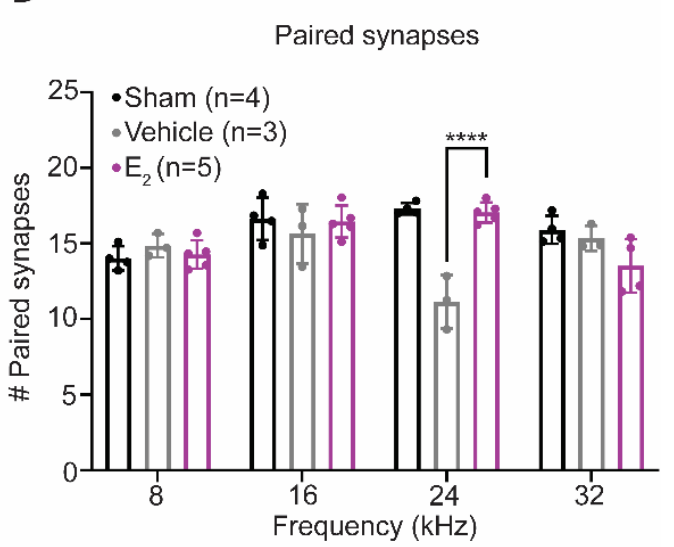

$\mathrm{H}$

$\mathrm{OHC}$ loss

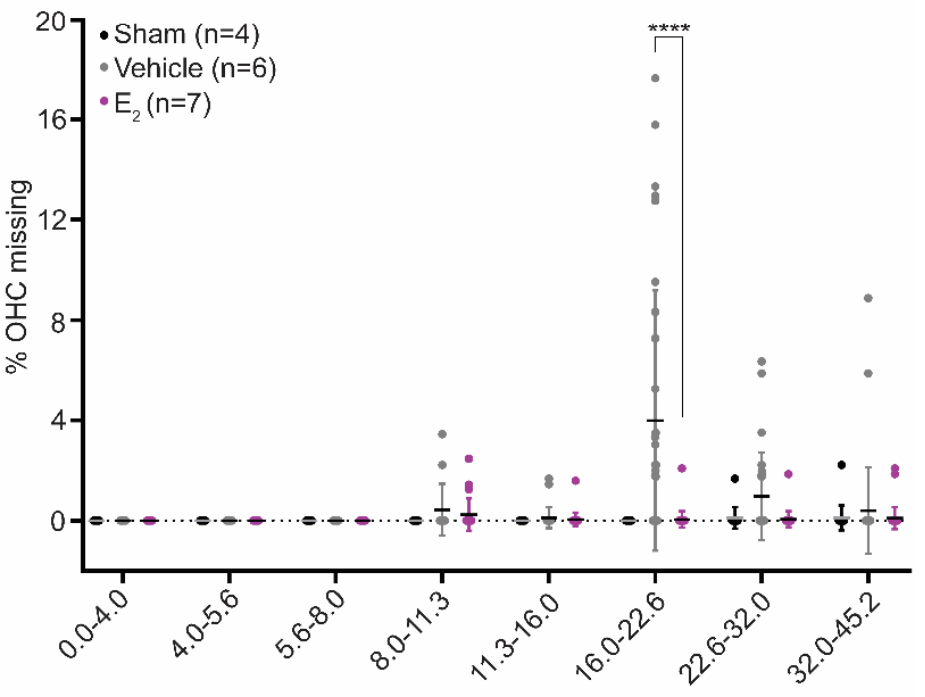

Frequency $(\mathrm{kHz})$

Figure 7. $\mathrm{E}_{2}$-replacement in gonadectomized female mice ameliorates cochlear synaptopathy and OHC loss following a TTS-inducing noise exposure. (A-C) Representative images of paired IHC-ANF synapses at $24 \mathrm{kHz} 1$-week postexposure in (A) sham-exposed mice, $(\mathbf{B})$ vehicle-treated mice, and $(\mathbf{C}) \mathrm{E}_{2}$-treated mice. Paired synapses were identified via the co-localization of CTBP2 (red) and GLUR2 (green). Sham animals were gonadectomized and vehicle-treated but not noise-exposed. (D) $E_{2}$-replacement $(150 \mu \mathrm{g} / \mathrm{kg})$ ameliorates cochlear synaptopathy at $24 \mathrm{kHz} 1$-week following a TTS-inducing noise ( $94 \mathrm{~dB}$ SPL, $8-16 \mathrm{kHz}, 2-\mathrm{h})(p<0.0001)$. Compared to a group of sham exposed mice, $\mathrm{E}_{2}$-treated mice display no loss of synapses at $24 \mathrm{kHz}$, while vehicle-treated mice display, on average, a loss off 5.9 synapses at this frequency. (E-G) Representative cytocochleograms 1-week post-exposure at the approximate cochlear location of $18-20 \mathrm{kHz}$ in (E) sham-exposed mice, $(\mathbf{F})$ vehicle-treated mice, and $(\mathbf{G}) \mathrm{E}_{2}$-treated mice. White arrows indicate missing OHCs. (H) Vehicle-treated mice display increased susceptibility to OHC loss 1-week following a TTS-inducing noise exposure. Compared to $\mathrm{E}_{2}$-treated female mice, vehicle-treated female mice displayed significantly increased $\mathrm{OHC}$ loss restricted to the frequencies between $16.0 \mathrm{kHz}$ and $22.6 \mathrm{kHz}(p<0.0001)$. Neither group of animals displayed significant $\mathrm{OHC}$ loss below $16 \mathrm{kHz}$ or above $22.6 \mathrm{kHz}$. Paired synapse counts and OHC loss were compared using a 2-way ANOVA followed by Sidak's multiple comparison test. Dotted lines in (A-C) represent the outline of a single inner hair cell. $n=$ number of ears, plots: mean \pm SD; scale bar in (C): $10 \mu \mathrm{m}$; scale bar in (G): $50 \mu \mathrm{m}$; ${ }^{* * * *} p<0.0001$.

\subsection{Gonadectomy Increases Susceptibility to OHC Loss}

Outer hair cell loss is typically not a pathophysiological outcome of exposure to TTS-inducing noise $[12,38,39]$. However, the effect of TTS-inducing noise on OHC survival has not been previously compared between intact and gonadectomized mice. 
We therefore performed cytocochleograms to examine OHC survival in the same cohort of animals 1-week post-exposure. As expected, $\mathrm{E}_{2}$-treated mice did not display any loss of $\mathrm{OHC}$. In contrast, compared to $\mathrm{E}_{2}$-treated mice, vehicle-treated mice displayed a $3.9 \%$ increase in $\mathrm{OHC}$ loss $(p<0.0001) 1$-week post-exposure that was restricted to frequencies between $16.0 \mathrm{kHz}$ and $22.6 \mathrm{kHz}$ (Figure 7E-H). Like the $\mathrm{E}_{2}$-treated mice, vehicle-treated mice did not display significant OHC loss below $16.0 \mathrm{kHz}$ or above $22.6 \mathrm{kHz}$.

\subsection{Canonical Estrogen Receptor Localization}

To identify possible mechanisms through which estrogen alters auditory physiology and confers protection against NIHL, we characterized the expression of estrogen receptors 1 and 2 (Esr1,Esr2) transcripts in male and female mice. Fluorescent in situ hybridization RNAscope ${ }^{\mathrm{TM}}$ assays were performed to localize the receptor transcripts to specific cell types in the cochlea, with representative images taken from the middle turn of the cochlea (Figure 8A-F). No sex differences in the localization of either Esr1 or Esr 2 were detected. In the organ of Corti, expression of Esr1 and Esr2 was observed at low levels in the IHCs, whereas the OHCs demonstrated no expression of either receptor (Figure 8A,D). Moderate levels of Esr1 and Esr2 expression were seen within the stria vascularis (SV), with Esr1 similarly distributed throughout the three cell layers comprising the SV (Figure 8B,E). Distribution of Esr2 mRNA appeared more highly expressed in the basal cell layer compared to the marginal and intermediate cells. In contrast to the organ of Corti and stria vascularis, the most abundant expression of estrogen receptors was observed within the SGNs (Figure 8C,F). Interestingly, while Esr1 expression was lower and diffuse throughout the SGNs, Esr 2 exhibited robust and highly specific expression in a subset of neurons.

To determine the identity of this SGN subtype, additional fluorescent in situ hybridization assays were performed using a probe for Lypd1, an type-1C SGN marker, in combination with a probe for Esr2 [10]. In both male and female mice, we found significantly greater co-expression of Lypd1 and Esr2 together versus Esr2 alone $(p<0.0001)$, suggesting Esr2 localization is primarily confined to the type-1C SGNs in the adult mouse cochlea (Figure 8G-I). 

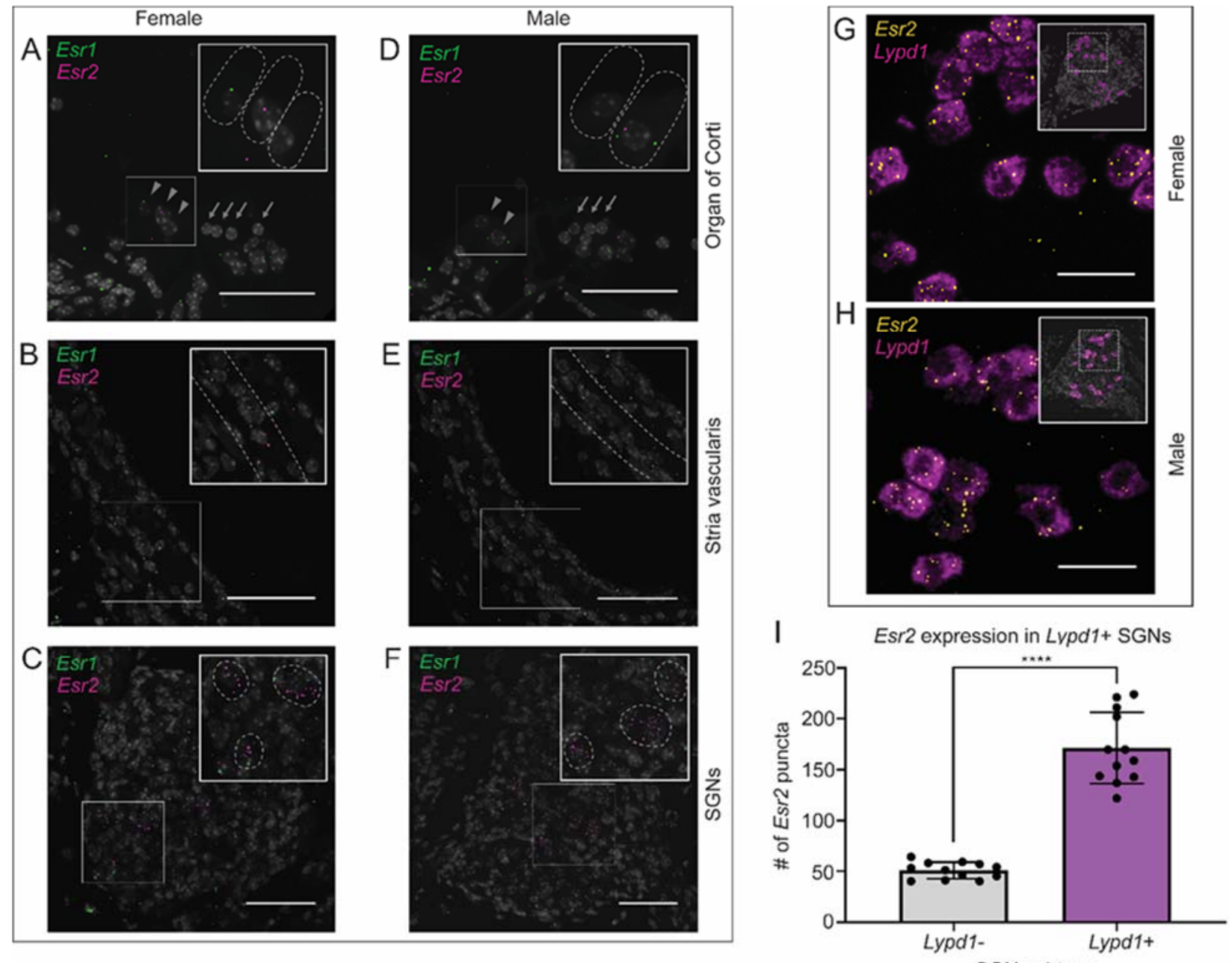

Figure 8. Fluorescent in situ hybridization of estrogen receptor 1 (Esr1) and estrogen receptor 2 (Esr2). mRNA expression in the organ of Corti, stria vascularis, and spiral ganglion neurons of both male and female mice (A-F). Esr1 (green puncta) and Esr2 (magenta puntca) are present at low levels in the inner hair cells of the organ of Corti, marked by grey arrowheads, but are absent in the outer hair cells, marked by grey arrows (A,D). Esr1 is expressed throughout the three cell layers of the stria vascularis, while Esr2 expression appears highest in the basal cell layer, marked by dashed grey lines (B,E). Esr1 expression is low and diffuse within the spiral ganglion neurons, while Esr2 expression appears highest in a specific neuronal subtype (C,F). Scale bars: $50 \mu \mathrm{m}$. (G,H) Esr2, represented by yellow punctate dots, is co-expressed with Lypd1, a type-1C SGN marker seen in magenta. (I) Esr2 expression is highest in type-1C SGNs compared to any other cell type in the spiral ganglion $\left(^{* * * *} p<0.0001\right.$; student's $t$-test). Scale bars: $25 \mu \mathrm{m}$.

\section{Discussion}

Our laboratory previously identified biological sex as a critical factor that influences the severity of hearing loss following noise exposure and showed that adult female mice are protected in comparison to males [16]. Here, we used a gonadectomy model to demonstrate that gonadal $\mathrm{E}_{2}$ underpins, at least partially, the relative protection in female mice. In the absence of endogenous gonadal hormones, we demonstrated that males and females are equally susceptible to noise exposure. Our data show that $E_{2}$-replacement in female mice ameliorates threshold shifts following PTS- and TTS-inducing noise exposures and reduces loss of $\mathrm{OHC}$ and paired synapses. Furthermore, to the best of our knowledge, our data reveal, for the first time, colocalization of Esr2 and type 1-C SGNs and suggest that protection from cochlear synaptopathy may occur through $\mathrm{E}_{2}$-mediated preservation of these neurons. 
$\mathrm{E}_{2}$-replacement increased $\mathrm{OHC}$ survival in female mice following both types of noise exposures. To our surprise, surgical gonadectomy without $\mathrm{E}_{2}$-replacement resulted in a focal loss of OHCs between $16.0 \mathrm{kHz}$ and $22.6 \mathrm{kHz}$ 1-week following a TTS-inducing noise exposure. Frequency-specific OHC loss has not generally been reported for any animal model following a TTS-inducing exposure [12,38,39], nor was frequency-specific OHC loss observed in intact female mice of the same strain (B6CBAF1/J) following a more intense PTS-inducing noise exposure [16]. These results suggest that OHCs in females are uniquely vulnerable to noise exposure in the absence of baseline levels of circulating gonadal steroid hormones and are prone to cell death even following less-intense noise exposures. The potential translational significance of this finding for post-menopausal women is supported by additional evidence demonstrating that the decrease in $\mathrm{E}_{2}$ levels associated with menopause prompts a decline in hearing sensitivity [40,41].

In mice exposed to TTS-inducing noise, $\mathrm{E}_{2}$-replacement prevented cochlear synaptopathy at $24 \mathrm{kHz}$, the frequency with the maximal CTS in our animal model. The observed protection from synaptopathy may occur via prevention of the uncoupling of the paired IHC-ANF synapses, synaptic regeneration, or a combination of both phenomena. Recent studies demonstrate the potential for synaptic regeneration as treatment with bisphosphonates 24-h post-exposure can reverse synaptopathy [42]. Histological evaluation at additional post-exposure timepoints is needed to discriminate the two proposed mechanisms.

Our data also demonstrate that $\mathrm{E}_{2}$-replacment is sufficient to modulate peripheral auditory physiology in the absence of noise exposure. In particular, we observed a robust effect of $E_{2}$-replacement on wave- 1 amplitude, where $E_{2}$-treated female mice displayed larger wave-1 amplitudes at all frequencies examined despite no differences in the number of paired IHC-ANF synapses. An increase in wave- 1 amplitudes in the absence of changes to paired synapse numbers could arise from the non-genomic actions of estrogens, which include the regulation of calcium signaling and cyclic adenosine monophosphate (cAMP). Previous studies demonstrate that estrogens potentiate L-type calcium channels like CaV1.3, which is found at the inner hair cell synapse [43,44]. An increase in cAMP and CaV1.3 conductance could lead to an increase in glutamate release [45]. The increase in glutamate release, in turn, could lead to an increase in the speed, or number, of spike generations and cause an increase in wave- 1 amplitude [46]. Further functional studies are required to investigate this hypothetical mechanism.

$E_{2}$ is a known ligand of the two classical estrogen receptors, ESR1 and ESR2. Upon binding with $\mathrm{E}_{2}$, ESR1 and ESR2 homo- and hetero-dimerize and translocate to the nucleus where they regulate transcription of target genes $[19,47]$. Previous reports suggest that ESR1 and ESR2 are both expressed in the cochlea of CBA inbred strains $[48,49]$ and that protein levels of ESR2 may be expressed at a higher level than ESR1 in the inner ear SGNs [48]. Furthermore, ESR2 has been functionally implicated in ARHL and NIHL [22,23]. Our data demonstrate localization of both Esr1 and Esr2 transcripts in the SGNs of intact adult male and female mice. However, we also show that Esr 2 localizes more specifically to type-1C SGNs. These data provide additional evidence to support our hypothesis that the protective effects of estrogen-signaling following noise exposure-in this case, the amelioration of cochlear synaptopathy following noise trauma - may be mediated via ESR2. Previous studies have suggested that synaptopathy-inducing noise results specifically in the retraction of type-1C fibers, suggesting $\mathrm{E}_{2}$-replacement protects against the loss of type-1C SGNs that characterizes synaptopathy $[9,10]$. In support of the histologic data that suggest $\mathrm{SGNs}$ are responsive to $\mathrm{E}_{2}$-treatment, we show that unexposed $\mathrm{E}_{2}$-treated female mice display increased $A B R$ wave- 1 amplitudes at all frequencies tested. Future studies should ask why type-IC SGNs may be protected in the presence of $E_{2}$.

In contrast to the robust expression detected in the SGNs, we detected no expression of Esr1 or Esr2 transcripts in the OHCs. A previous report demonstrated faint immunostaining of ESR1 and negative immunostaining of ESR2 in the OHCs of CBA mice [49]. Nevertheless, $\mathrm{E}_{2}$-treated mice displayed improved DPOAE thresholds-a proxy for OHC function-in the absence of changes to the endocochlear potential. These data suggest that the effect of 
$\mathrm{E}_{2}$ on $\mathrm{OHC}$ physiology is not likely to be mediated via the canonical estrogen receptors ESR1 or ESR2 and may be modulated via another estrogen receptor such as GPER1, the estrogen-related receptors (ESRR $\alpha, \operatorname{ESRR} \beta$, and ESRR $\gamma$ ), through a more complex interaction between the classical and related receptors [50], or through increased activation of the projections of the medial olivocochlear bundle [51].

We report, for the first time, an $\mathrm{E}_{2}$-mediated protection against cochlear synaptopathy following noise exposure. The literature provides examples of $\mathrm{E}_{2}$-mediated regulation of synaptic plasticity elsewhere [52-54]. In the central nervous system (CNS), $\mathrm{E}_{2}$-signalingparticularly through the classical estrogen receptor ESR2-has been shown to enhance synaptic plasticity through an increase in expression of TRKB and BDNF [55]. In the cochlea, TRKB and BDNF have been shown to prevent neuronal retraction following noise exposure- the currently known pathophysiology to underpin cochlear synaptopathy [56,57].

The role of gonadal $\mathrm{E}_{2}$ as a neuroprotectant and neuromodulator is also well-established [58,59]. Ovariectomy of female mice induced an increase in amyloid beta plaques in a model of Alzheimer's disease, while $E_{2}$-replacement partially ameliorated this effect [60]. Additional studies demonstrated that surgical ovariectomy without $\mathrm{E}_{2}$-replacement increases vulnerability of hippocampal neurons in a model of glutamatergic excitotoxicity, and that prophylactic $\mathrm{E}_{2}$-replacement prevented this vulnerability [61]. Of significance, glutamatergic excitotoxicity is thought to be a key mediator of noise-induced cochlear synaptopathy [62-64]. Taken together, our data show an $\mathrm{E}_{2}$-mediated otoprotective effect from noise-induced synaptopathy that is consistent with the role of $\mathrm{E}_{2}$-signaling in the CNS and likely mediated via ESR2. These findings are clinically significant, as ESR2-mediated signaling is non-feminizing, and FDA-approved ESR2-modulators are already available $[65,66]$.

Our data further indicate that the otoprotective effects of gonadal $\mathrm{E}_{2}$ against PTSinducing noise exposure may be confined to females, and that females and males are equally susceptible to PTS-inducing noise when devoid of their gonadal hormones. Additional investigation is needed to determine whether $\mathrm{E}_{2}$ is protective against TTS-inducing noise in male mice. Consistent with our findings, in a model of Parkinson's disease, $\mathrm{E}_{2}$-replacement in gonadectomized female rats conferred neuroprotection, while $\mathrm{E}_{2}$-replacement in gonadectomized males proved deleterious [67]. Conversely, in other models, $\mathrm{E}_{2}$-replacement has shown beneficial effects in gonadectomized rats of both sexes. $E_{2}$-replacement has shown to suppress the increase in brain mitochondrial oxidative stress following gonadectomy [68] and confer neuroprotection in an experimental model of stoke [69,70]. Taken together, these reports indicate a tissue-specific interaction between biological sex and the neuroprotective effects of gonadal $\mathrm{E}_{2}$.

The system-specific similarities and differences in the neuroprotective actions of $E_{2}$ in males and females are likely due to a combination of organizational and activational effects. Organizational effects arise from changes during the developmental hard wiring of the brain, whereas activational effects arise from modulation by circulating gonadal hormones [59,71]. In support of an organizational component, both male and female ESR2 $\mathrm{KO}$ mice show increased susceptibility to TTS-inducing noise [22]. Additional evidence for an organizational component in the auditory system arise from studies of ESRR $\alpha$, $\operatorname{ESRR} \beta$, and ESRR $\gamma$. These receptors do not bind $\mathrm{E}_{2}$, but nevertheless regulate many of the same transcriptional targets as ESR1 and ESR2 [50]. At least one identified human polymorphism in ESRR $\beta$ predicts audiometric TTS in musicians of both sexes, while additional polymorphisms in ESRR $\beta$ and ESRR $\gamma$ cause non-syndromic, congenital hearing impairment and are also implicated in the maintenance of hearing [72-75]. On the other hand, our data suggest $E_{2}$ also influences susceptibility to/protection from NIHL via activational effects. Elimination of gonadal steroid hormones via surgical gonadectomy abolishes - and $E_{2}$-replacement re-establishes—an innate relative protection from PTSinducing noise in adult female mice in comparison to males. Additional evidence in humans demonstrating changes in hearing sensitivity and DPOAE amplitudes in preand post-menopausal women also implicate activational effects of $\mathrm{E}_{2}$-signaling in the modulation of auditory physiology [76,77]. 
The findings presented here are immediately clinically relevant, not only for the treatment of NIHL, but also for the treatment of other diseases of the auditory and vestibular system, such as Meniere's Disease, in which $\mathrm{E}_{2}$ levels can correlate with symptom severity [77]. The characterization of sex-differences in NIHL and ARHL-which share common mechanisms [78,79] — figures to bear heavily on the development of new therapeutics. In fact, previous reports already suggest that experimental NIHL therapeutics may exhibit sex-dependent efficacy [16,17]. Furthermore, existing FDA-approved, tissue-specific ESR2 modulators, like raloxifene (currently approved for treatment of osteoporosis in postmenopausal women), have been shown to confer neuroprotective effects in a mouse model of epilepsy [80], rendering such drugs as potential candidates for protection of hearing.

\section{Materials and Methods}

\subsection{Animals}

All animals utilized in the experiments were B6CBAF1/J mice (Jackson Laboratory, Bar Harbor, ME, USA; Stock No 100011). These mice are F1 progeny from a cross between C57BL/6J and CBA/J, which eliminates the influence of strain-specific recessively inherited traits such as resistance or susceptibility to ARHL, NIHL, or sound-induced seizures [16]. The animal facility is controlled for temperature and humidity and has a 12-h light/dark cycle (lights on at 7 a.m.). Mice were provided with dry food and water ad libitum. All surgical and experimental procedures took place during the animals' light phase. Animals were euthanized by $\mathrm{CO}_{2}$ asphyxiation or terminal perfusion with $4 \%$ paraformaldehyde and then decapitated.

DPOAE testing and lateral wall EP measurement were completed at the Washington University School of Medicine in St. Louis using a separate cohort of animals. Round window EP measurements were completed at the National Institute on Deafness and other Communication Disorders using a separate cohort of animals. All other animal experiments were completed at the University of Maryland School of Medicine. No animals were transported between institutions at any time.

\subsection{Gonadectomy}

Mice were gonadectomized at 8-weeks of age. Anesthesia was achieved with isoflurane gas. In the female mice, bilateral ovariectomy was performed by making a $5 \mathrm{~mm}$, longitudinal, dorsal incision through the skin and muscle wall. The ovary was separated from the uterus lateral to the oviduct using electrocautery, and the uterine horn was repositioned in the abdominal cavity. The muscle wall was closed using a 4-0 poliglecaprone suture (MWI Animal Health, Boise, ID, USA), and the skin was closed using a 4-0 nylon suture (MWI Animal Health, ID). The same procedure was then repeated on the contralateral ovary. In the male mice, bilateral gonadectomy was performed by making a single $2-3 \mathrm{~mm}$, longitudinal, ventral incision through the scrotum. The testes were separated from the seminal vesicles with electrocautery. The skin was closed as described above. Incision sites were treated with a 2.5\% lidocaine and 2.5\% Prilocaine Cream (Akorn, Lake Forest, IL, USA) and Bacitracin Zinc antibiotic ointment (Trifecta Pharmaceuticals, Fort Lauderdale, FL, USA). Carprofen $(0.05 \mathrm{mg} / \mathrm{kg})$ was administered by subcutaneous injection immediately before the surgical procedure and 24-h post-operatively for analgesia.

\subsection{Subcutaneous Pump Placement}

Eight-week-old male and female mice underwent surgical gonadectomy as described above. During the procedure, animals were implanted with the Alzet $1004^{\circledR}$ micro-osmotic pump (DURECT Corporation, Cupertino, CA, USA). In female mice, pumps were implanted subcutaneously via the incision created during the ovariectomy. In male mice, a $1 \mathrm{~cm}$, dorsal, longitudinal incision was made between the scapulae. To offset the position of the pump relative to the incision, a subcutaneous pocket was developed by blunt dissection lateral to the incision. All animals recovered for 5-7 days prior to the baseline ABR. 


\subsection{Hormonal Treatments}

We utilized three hormonal regimens to generate the data presented in this manuscript. In our experiments evaluating the acute effects of hormone replacement on auditory physiology in the absence of noise exposure, we utilized a series of daily subcutaneous injections administered over a period of 3-4 days. Mice in the NIHL experiments received continuous hormonal replacement for the duration of the studies, a period of 3-4 weeks, which was achieved using either implanted subcutaneous pumps or serial subcutaneous injections. Pumps were utilized in the initial NIHL experiments. Subsequent experiments utilized serial subcutaneous injections, which provided greater control and increased confidence in successful hormone delivery.

\subsubsection{Acute Hormonal Supplementation Using Subcutaneous Injections}

Mice were administered daily subcutaneous injections of $\mathrm{E}_{2}$ (Sigma-Aldrich, St. Louis, MO, USA) $(300 \mu \mathrm{g} / \mathrm{kg})$ reconstituted in sesame oil (vehicle) (Sigma-Aldrich)—or vehicle only-for a period of 3-4 days. This dose was chosen to acutely elevate serum $E_{2}$ to supraphysiologic levels prior to electrophysiological evaluation of baseline auditory function.

\subsubsection{Continuous Hormonal Supplementation Using Osmotic Pumps}

The Alzet ${ }^{\circledR} 1004$ micro-osmotic pump was loaded with either $17 \beta$-estradiol $\left(E_{2}\right)$ (Sigma-Aldrich) at a concentration of $38 \mu \mathrm{g} / 100 \mu \mathrm{L}$ in propylene glycol (PPG) or PPG only. The pump delivered $0.11 \mu \mathrm{L} / \mathrm{h}$ of the loaded solutions at a steady release rate to administer a dose of $1 \mu \mathrm{g}$ of $E_{2} /$ day. Drug administration began immediately after pump implantation and continued the entire duration of the study. Serum $\mathrm{E}_{2}$ delivery was confirmed qualitatively and quantitatively at the conclusion of the study, four weeks after implantation (Figure A1). Following euthanasia via $\mathrm{CO}_{2}$ asphyxiation, the female uterine horns and the male seminal vesicles were exposed and photographed for comparison (Figure A1). Trunk blood was collected, and the sera were processed for estradiol levels as measured via ELISA (ES180S-100, CalBiotech, El Cajon, CA, USA) performed at University of Virginia Ligand Assay and Analysis Core) (Figure A1).

\subsubsection{Continuous Hormonal Supplementation Using Subcutaneous Injections}

Two to 3 days following surgical gonadectomy, mice were administered subcutaneous injections of $17 \beta$-estradiol-3-benzoate (EB) (Sigma-Aldrich) at a concentration of $150 \mu \mathrm{gg} / \mathrm{kg}$ reconstituted in sesame oil (vehicle) (Sigma-Aldrich)—or the vehicle only—every other day for the duration of the study. EB is a synthetic pro-drug ester of $17 \beta$-estradiol that is deesterified by nonspecific steroidal esterases to produce biologically active $\mathrm{E}_{2}$ in vivo $[81,82]$. EB delivery is a commonly used method of $\mathrm{E}_{2}$ replacement that permits administration of subcutaneous injections every other day rather than every day due to its longer half-life relative to $E_{2}$. Mice that received $E_{2}$-replacement via injections of $E B$ will, from hereon, be described as $E_{2}$-treated or as having received $E_{2}$-replacement following euthanasia, the female uterine horns were exposed and photographed for comparison to confirm successful $\mathrm{E}_{2}$ replacement (Figure A1).

\subsection{Noise Exposures}

Noise exposures were performed using the methods previously described [16]. All mice underwent calibrated noise exposure at 10-weeks of age at the same time of day (8:00 am). Octave-band noise centered at $11.3 \mathrm{kHz}(8-16 \mathrm{kHz})$ was delivered for 2-h using the Fostex FT17H tweeter (Fostex, Tokyo, Japan). Noise was delivered at $102.5 \mathrm{~dB}$ sound pressure level (SPL) to induce a PTS or at $94 \mathrm{~dB}$ SPL to induce a TTS with cochlear synaptopathy. Calibration was achieved with a measurement microphone (PCB Piezotronics, Depew, NY, USA) placed at the same distance from the tweeter as the mouse's ears. The tweeter was placed $20 \mathrm{~cm}$ above the mice and the sound level was measured to be within $0.5 \mathrm{~dB}$ of the target level. During the exposure, mice were placed in a custom holder constructed of perforated aluminum sheets $(18 \times 15 \times 5 \mathrm{~cm})$ with eight 
equal sized chambers $(4.5 \times 7.5 \times 5 \mathrm{~cm})$ in an acoustically controlled box (IAC Acoustics, North Aurora, IL, USA). Only the four central compartments were used to expose a maximum of four mice simultaneously. The animals were awake and unrestrained throughout the exposure.

\subsection{Auditory Brainstem Response (ABR)}

ABRs were performed using methods described previously [16]. ABRs were recorded at baseline (5-7 days pre-exposure), 24-h after the noise exposure to quantify the compound threshold shift (CTS), and 1-2 weeks after the noise exposure to quantify the permanent threshold shift (PTS) or to confirm a temporary threshold shift (TTS). Animals were anesthetized using an intraperitoneal injection of ketamine $(100 \mathrm{mg} / \mathrm{kg}$ ) (Vet One, Boise, ID, USA) and xylazine ( $20 \mathrm{mg} / \mathrm{kg}$ ) (Akorn, Lake Forest, IL, USA). Using the RZ6 recording system (Tucker-Davis Technologies (TDT), Alachua, FL, USA), hearing thresholds were determined at $8 \mathrm{kHz}, 16 \mathrm{kHz}, 24 \mathrm{kHz}$, and $32 \mathrm{kHz}$ in an acoustically controlled box (IAC Acoustics, IL). Once surgical levels of anesthesia were achieved, animals were positioned so that they directly faced the tweeter with their ears $10 \mathrm{~cm}$ from the front of the tweeter. Subcutaneous electrodes were placed at the post-auricular area of the left and right ears, and at the vertex of the skull for the reference. The ground electrode was placed at the base of the tail. Output stimuli were calibrated with a measurement microphone (PCB Piezotronics, NY) placed at the same distance from the tweeter as the mouse's ears $(10 \mathrm{~cm})$. Frequency-specific tone bursts 2.5 milliseconds $(\mathrm{ms})$ long, with a $0.5 \mathrm{~ms}$ sinusoidal on- and off-ramp were delivered with alternating polarity beginning at $90 \mathrm{~dB}$ SPL. Tone bursts were progressively decreased by $5 \mathrm{~dB}$ until $10 \mathrm{~dB}$ below the measurable hearing threshold for each mouse. Electrophysiologic responses to each tone stimulus, filtered between $300 \mathrm{~Hz}$ and $3000 \mathrm{~Hz}$, were recorded for $10 \mathrm{~ms}$ starting at the onset of the tone, with a total of 512 sweeps at a rate of 21 sweeps/second, and then averaged at each sound level and frequency tested. The responses from each ear were recorded simultaneously. The hearing threshold was defined as the lowest level at which either ABR waves 1 or 2 could be identified. Thresholds were averaged between the two ears and reported as a single value per animal.

Suprathreshold wave- 1 amplitudes were extracted offline according to methods described previously [16]. Peak-to-trough wave-1 amplitude was calculated using the maximum positive deflection after $1 \mathrm{~ms}$ in the recording and the subsequent maximum negative deflection. Wave-1 amplitudes were averaged between the two ears and reported as a single value per animal.

\subsection{Distortion Product Otoacoustic Emissions (DPOAE)}

DPOAE data (2f1-f2) were collected at the Washington University School of Medicine in St Louis. All recordings were from the left ear. Animals were anesthetized using ketamine and xylazine $(80 / 15 \mathrm{mg} / \mathrm{kg}$, intraperitoneally) and positioned dorsally in a custom headholder. Body temperature was monitored throughout testing using a rectal probe and maintained at $37.5 \pm 1.0{ }^{\circ} \mathrm{C}$ using a DC current-based isothermal pad (Frederick Haer, Bowdoin, ME, USA). DPOAE input/output relations were obtained for f2's of 10, 20, and $28.3 \mathrm{kHz}$ using Otoacoustic Emission Average (EMAV) (Boys Town National Research Hospital, Boys Town, NE, USA) in conjunction with TDT and custom hardware. $\mathrm{f} 1$ frequencies were given by $\mathrm{f} 2 / 1.2$. The level of $\mathrm{f} 1$ (L1) varied from 10 to $90 \mathrm{~dB}$ SPL in $5 \mathrm{~dB}$ steps while the level of $\mathrm{f} 2$ (L2) varied as L1-10 dB. Stimuli were delivered to the ear using a custom coupler inserted using an operating scope. Each channel was output to a TDT EC-1 speaker. DPOAE responses were recorded using a Knowles FC-23652-P16 microphone calibrated to $40 \mathrm{kHz}$ and digitized at $192 \mathrm{kHz}$. DPOAE thresholds were defined as the minimum sound level required to produce a response of at least $-5 \mathrm{~dB}$ SPL, well above typical noise levels of about $-20 \mathrm{~dB}$ SPL. When sound levels straddled this response size, the threshold was taken to be the midpoint. 


\subsection{Endocochlear Potential}

\subsubsection{Round Window}

Data were collected at the National institute on Deafness and Other Communication Disorders in Bethesda, MD. Methods for endocochlear potential (EP) measurement from the round window have been described previously [83-85] Here, mice were anesthetized with 2,2,2-tribromoethanol (T4842, Sigma-Aldrich, St. Louis, MO, USA) at a dose of $0.35 \mathrm{mg} / \mathrm{g}$ body weight. EP measurements were made using glass microelectrodes inserted into the round window and through the basilar membrane of the first turn of the cochlea. Induction of anoxia, allowing measurement of anoxic-state EP, was accomplished by intramuscular injection of succinylcholine chloride $(0.1 \mu \mathrm{g} / \mathrm{g}$, NDC-0409-6629-02, Pfizer, New York, NY, USA) after establishment of deep anesthesia followed by additional injection of 2,2,2-Tribromoethanol (T4842, Sigma-Aldrich, St. Louis, MO, USA). Anoxic-state EP provides an indicator of passive sensory hair cell polarization. In the presence of functional hair cells, the anoxic-state EP is negative, whereas the EP is zero if the hair cells are not functional. Data were recorded digitally (Digidata 1440A and AxoScope 10; Molecular Devices, San Jose, CA, USA) and analyzed using Clampfit10 (RRID: SCR_011323, Molecular Devices, San Jose, CA, USA). EP measurements were obtained from gonadectomized female mice that received subcutaneous injections of vehicle ( $n=6$ mice) or $\mathrm{E}_{2}(n=8$ mice) as described above with the examiner blinded to treatment received.

\subsubsection{Lateral Wall}

Data were collected at the Washington University School of Medicine in St Louis. Methods for EP measurement via the lateral wall were performed as previously described [86]. Briefly, animals underwent a single terminal EP measurement from the cochlear lower basal turn of the left ear. Animals were anesthetized $(60 \mathrm{mg} / \mathrm{kg}$ sodium pentobarbital, IP) (Hospira Incorporated, Lake Forest, IL, USA) and positioned ventrally in a custom headholder. Core temperature was maintained at $37.5 \pm 1.0^{\circ} \mathrm{C}$ using a thermostatically controlled heating pad in conjunction with a rectal probe (Yellow Springs Instruments Model 73A) (YSI Incorporated, Yellow Springs, OH, USA). An incision was made along the midline of the neck and soft tissues were blunt dissected and displaced laterally to expose the trachea and left bulla. A tracheostomy was then made and the musculature over the bulla was cut posteriorly to expose the bone overlying the round window. Using a fine drill, a hole was made in the left cochlear capsule directly over scala media of the lower basal turn using strial pigment as a guide. Glass capillary pipettes (20-40 M $\Omega$ ) filled with $0.15 \mathrm{M} \mathrm{KCl}$ were mounted on a hydraulic microdrive (Frederick Haer, ME) and advanced until a stable positive potential was observed that did not change with increased electrode depth. The signal from the recording electrode was led to an AM Systems Model 1600 intracellular amplifier (A-M Systems, Sequim, WA, USA). A silver/silver chloride ball inserted into the neck muscles served as ground.

\subsection{Immunostaining}

Immunostaining was performed as previously described [16] with minor modifications. Briefly, tissue was fixed by transcardial perfusion of $4 \%$ paraformaldehyde (PFA, Alfa Aesar, Haverhill, MA, USA), followed by harvest of the temporal bones and further fixation in $4 \%$ PFA at $4{ }^{\circ} \mathrm{C}$ overnight. After adequate decalcification by incubation in $500 \mathrm{mM}$ EDTA (3-6 days), the cochlear ducts were dissected as described by the Eaton-Peabody Laboratories [87]. The tissue was permeabilized with PBS-0.3\% Triton X-100 (Sigma-Aldrich, St. Louis, MO, USA) and blocked in permeabilization buffer supplemented with $5 \%$ normal goat serum (Cell Signaling Technology, Danvers, MA, USA). Pre-synaptic ribbons and post-synaptic densities were labelled using a monoclonal mouse anti-CtBP2 antibody (1:200, BD Biosciences, San Jose, CA, USA) and a monoclonal mouse anti-GluR2 antibody (1:2000, Sigma-Aldrich, St. Louis, MO, USA), respectively, followed by incubation with the corresponding secondary antibodies, goat anti-mouse IgG2 Alexa Fluor ${ }^{\circledR} 488$ and goat anti-mouse IgG1 Alexa Fluor ${ }^{\circledR} 568$ (1:1000, ThermoFisher Scientific, Waltham, MA, USA). 
Nuclei were counterstained with DAPI. The labelled tissue was mounted with the ProLong Gold antifade reagent (ThermoFisher Scientific, Waltham, MA, USA).

\subsection{Cochlear Frequency Mapping}

Frequency mapping was performed as previously described [16]. Tissue was imaged using a Nikon Eclipse E600 fluorescence microscope (Nikon, Tokyo, Japan) equipped with an Infinity 3 camera (Lumenera, Ottawa, ON, Canada) and processing the images with the Measure Line plugin for ImageJ (version 1.52A, National Institutes of Health, Bethesda, MD, USA) developed by the Eaton-Peabody Laboratories, as described in [87] (https:/ / www. masseyeandear.org/research/otolaryngology/eaton-peabody-laboratories/histology-core, accessed on 29 September 2020).

\subsubsection{Synapse Counts}

Stained tissues were imaged at the regions around $8 \mathrm{kHz}, 16 \mathrm{kHz}, 24 \mathrm{kHz}, 32 \mathrm{kHz}$, and $45 \mathrm{kHz}$ using a Nikon W1 spinning disk confocal on a Nikon Ti2 inverted microscope (Nikon, Japan) using a $60 \times$ oil objective and $0.2 \mu \mathrm{m}$ sections. Paired synapses were identified via the co-localization of GLUR2 and CTBP2. Synapses were counted on Z-stacks using the ImageJ Cell Counter plugin.

\subsubsection{Cytocochleograms}

Outer hair cell nuclei counterstained with DAPI were imaged throughout the length of the cochlea using a NikonEclipse E600 microscope (Nikon, Japan) equipped with an Infinity 3 camera (Lumenera, Ottawa, Canada). The counts were expressed as percentage of missing hair cells in $2 \mathrm{kHz}$ intervals and binned within the following frequency intervals: $0.0-4.0 \mathrm{kHz}, 4.0-5.6 \mathrm{kHz}, 5.6-8.0 \mathrm{kHz}, 8.0-11.3 \mathrm{kHz}, 11.3-16.0 \mathrm{kHz}, 16.0-22.6 \mathrm{kHz}$, $22.6-32.0 \mathrm{kHz}, 32.0-45.2 \mathrm{kHz}, 45.2-55.0 \mathrm{kHz}$.

\subsection{In Situ Hybridization}

Tissue for the fluorescent in situ hybridization assays was obtained from intact male and female ( $n=5$ per sex) wildtype B6CBAF1/J mice (Jackson Laboratory, ME). At 10-weeks of age, mice were euthanized via $\mathrm{CO}_{2}$ asphyxiation followed by decapitation. Immediately following euthanasia, temporal bones were harvested from the head. The round and oval windows of the cochlea were opened, and a small opening was made in the apex cochlea to allow for increased perfusion during fixation. The temporal bones were fixed overnight at $4{ }^{\circ} \mathrm{C}$ in freshly made RNase free $4 \%$ paraformaldehyde (Alfa Aesar, Haverhill, MA, USA) in sterile $1 \times$ phosphate-buffered saline (Corning Inc., Corning NY, USA), then decalcified in $150 \mathrm{mM}$ EDTA (Quality Biological, Gaithersburg, MD, USA) at $4{ }^{\circ} \mathrm{C}$ for 3 days. Decalcified ears were processed by a sucrose gradient and embedded in SCEM tissue embedding medium (Section-Lab Co., Ltd., Hiroshima, Japan). Frozen tissue was cryosectioned at $12 \mu \mathrm{m}$ thickness on a Leica CM 1850 cryostat microtome (Leica, Vienna, Austria).

The fluorescent in situ hybridization assay was performed as described in the RNAscope ${ }^{\mathrm{TM}}$ Multiplex Fluorescent v2 protocol (Advanced Cell Diagnostics, Newark, CA, USA), using the RNAscope ${ }^{\mathrm{TM}}$ Multiplex Fluorescent Reagent Kit v2 (Cat No. 323100) and three RNAscope ${ }^{\mathrm{TM}}$ probes, ESR1 (Cat No. 478201-C3), ESR2 (Cat No. 316121-C2), and LYPD1 (Cat No. 318361). Images were taken at $40 \times$ magnification at the apical, middle, and basal turns of the cochlea using a Nikon W1 spinning disk confocal microscope (University of Maryland School of Medicine Center for Innovative Biomedical Resources [Confocal Microscopy Facility]-Baltimore, MD, USA). Image processing was performed with the Fiji ImageJ software to enhance signal clarity.

Quantification of Esr2 and Lypd1 co-expression was performed using the QuPath software according to the methods described in the QuPath RNA ISH Analysis guide (Advanced Cell Diagnostics, CA). Briefly, the spiral ganglion area was circled, and individual neurons were outlined using the 'Cell detection' program. Puncta for Esr2 were identified using the 'Subcellular detection' feature and the detection parameters were 
adjusted to distinguish positive signals from the background. Co-expression was defined by the number of Esr2 puncta overlapping with Lypd1 puncta.

\subsection{Statistics}

All statistical analyses were performed using Prism 8 software (GraphPad, San Diego, CA, USA). Analyses of auditory thresholds were completed within groups using a repeated measure (RM) 2-way ANOVA (treatment $\times$ frequency) followed by Sidak's multiple comparison test, or between groups using a 2-way (treatment $\times$ frequency) or 3-way (treatment $\times$ frequency $\times$ biological sex) ANOVA followed by Tukey's post-hoc test. Within-group analyses of DPOAE thresholds were completed using a 2-way ANOVA (treatment $\times$ frequency) followed by Sidak's multiple comparison test. Analyses of wave- 1 amplitudes were completed within groups at each frequency using a RM2-way ANOVA (treatment $\times$ stimulus intensity) followed by Sidak's multiple comparison test, or between groups at each frequency using a 3-way ANOVA (treatment $\times$ stimulus intensity $\times$ noise exposure) followed by Tukey's post hoc test. Analyses of OHC loss and paired synapses counts between groups were completed using a 2-way ANOVA (treatment $\times$ frequency) followed by Sidak's multiple comparison test. Analyses of endocochlear potentials and RNAscope $^{\mathrm{TM}}$ assays were completed using a student's $t$-test. An adjusted $p$-value of $<0.05$ was set as the threshold for statistical significance for all pairwise comparisons. F-scores for main effects of treatment and biological sex are provided in Table 1.

\section{Conclusions}

In conclusion, our data suggest that gonadal $\mathrm{E}_{2}$ protects against $\mathrm{NIHL}$, and that this $\mathrm{E}_{2}$-conferred protection may be sex-dependent. $\mathrm{E}_{2}$-replacement in gonadectomized adult female mice reduces hearing loss following both a PTS-inducing and TTS-inducing noise exposure. Histological analysis of cochlear tissue demonstrates that gonadectomy increases susceptibility to, and $\mathrm{E}_{2}$-replacement protects against, loss of $\mathrm{OHC}$ and the synaptic uncoupling of IHCs and SGNs following noise exposure. Furthermore, $\mathrm{E}_{2}$-replacement in gonadectomized female mice modulates the ABR and $\mathrm{OHC}$ physiology in the absence of noise exposure, providing additional evidence of $\mathrm{E}_{2}$ 's multi-modal modulatory capacity. Taken together, our data present $\mathrm{E}_{2}$ signaling pathways as potential therapeutic targets to mitigate noise-induced hearing loss.

Author Contributions: Conceptualization, B.S., J.A.M., D.A.D., B.M., R.C., R.H.; Methodology, B.S., J.A.M., B.M., R.H.; Validation, B.S., J.A.M., B.M., R.H., K.K.O., M.H., R.O., E.L.; Formal Analysis: B.S., B.M., R.H.; Investigation, B.S., R.C., E.L., B.M., K.K.O., M.A.R., K.D., J.E., S.V., M.M., R.O.; Writing-Original Draft Preparation, B.S., R.H.; Writing—Review \& Editing, B.S., J.A.M., B.M., E.L., D.A.D., M.A.R., K.K.O., M.H., R.H.; Visualization, B.S., E.L.; Supervision, B.S., B.M., R.H.; Project Administration, B.S., B.M., R.H.; Funding Acquisition, M.A.R., M.H., R.H. All authors have read and agreed to the published version of the manuscript.

Funding: This work is supported by the National Institutes of Health (NIH) R01DC013817 (R.H.), the Department of Defense MR130240 (R.H.), Department of Defense W81XWH2110578 (R.H.), and the Carolyn Frenkil Foundation (R.H.). Additionally, this work was supported (in part) by the Intramural Research Program of the NIH, NIDCD Z01DC000088 (M.H.) and NIH, NIDCD R01DC014712 (M.R.).

Institutional Review Board Statement: All procedures involving animals were carried out in accordance with the National Institutes of Health Guide for the Care and Use of Laboratory Animals and were approved by the Animal Care Committee at the University of Maryland (protocol numbers 1015003, 0915006, 0918005, and 0818004), the National Institute on Deafness and Other Communication Disorders (1379), and the Washington University in St. Louis School of Medicine (20-0368).

Informed Consent Statement: Not applicable.

Acknowledgments: We would like to thank Kevin P. Rose (University of Maryland School of Medicine) for technical assistance in preparation of the figures and Sunayana Mitra for technical assistance with ABRs. 
Conflicts of Interest: The authors declare no conflict of interest.

\section{Appendix A}

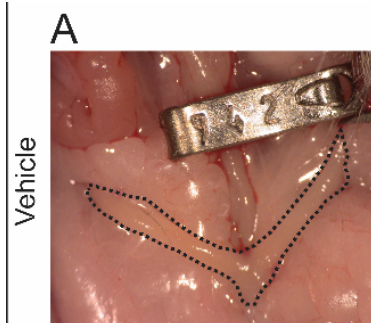

C

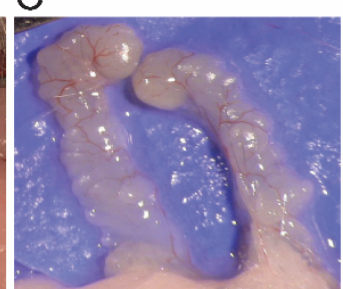

$\mathrm{B}$

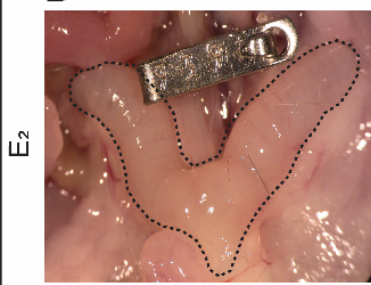

Osmotic Pump

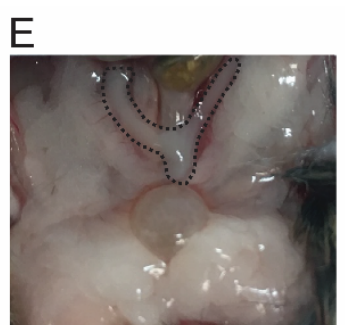

$\mathrm{F}$

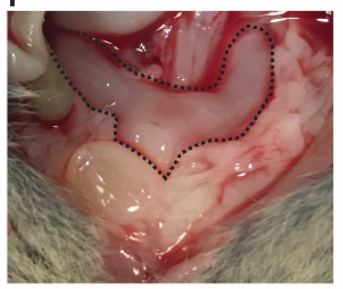

Sub-Q Injections

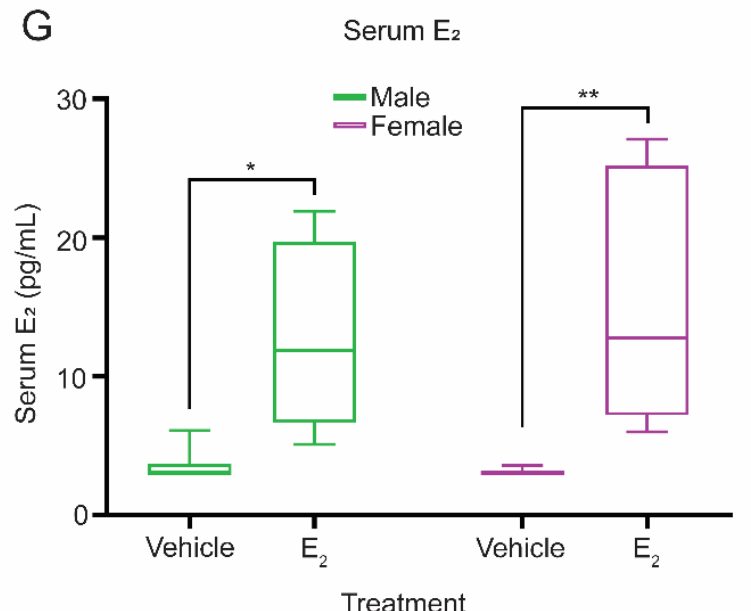

Figure A1. Qualitative and quantitative assessment of $E_{2}$ delivery. (A-F) Representative photographs of the uterine horns and seminal vesicles of gonadectomized female and male mice administered either vehicle or vehicle/ $E_{2}$. The left two columns depict qualitative changes to uterine horns $(\mathbf{A}, \mathbf{B})$ and seminal vesicles $(\mathbf{C}, \mathbf{D})$ with $\mathrm{E}_{2}$-replacement delivered via an osmotic pump, while the right column depicts qualitative changes to the female uterine horns $(\mathbf{E}, \mathbf{F})$ when $\mathrm{E}_{2}$-replacement is administered via subcutaneous injections. (G) Quantitative assessment of serum $\mathrm{E}_{2}$ levels collected from the trunk blood of vehicle-treated males $(n=8)$ and females $(n=7)$ and $\mathrm{E}_{2}$-treated males $(n=8)$ and females $(n=8)$ when treatments were administered via an osmotic pump. Serum estradiol levels were compared using a 2-way ANOVA (treatment $\times$ biological sex) followed by Tukey's post-hoc test. Box plots: minimum value, 1st quartile, median, 3rd quartile, maximum value; ${ }^{*} p<0.05,{ }^{* *} p<0.01$. 
Table A1. F-scores for main effects of treatment and biological sex for the 2-way and 3-way ANOVAs.

\begin{tabular}{|c|c|c|c|c|}
\hline & & Main Effect & F-Score & $p$-Value \\
\hline \multicolumn{5}{|l|}{ Baseline Physiology } \\
\hline ABR Thresholds & & Treatment & 28.53 & $<0.0001$ \\
\hline \multicolumn{5}{|l|}{ Wave-1 Amplitudes } \\
\hline & $8 \mathrm{kHz}$ & Treatment & 57.07 & $<0.0001$ \\
\hline & $16 \mathrm{kHz}$ & Treatment & 39.34 & $<0.0001$ \\
\hline & $24 \mathrm{kHz}$ & Treatment & 43.79 & $<0.0001$ \\
\hline & $32 \mathrm{kHz}$ & Treatment & 32.35 & $<0.0001$ \\
\hline \multicolumn{5}{|l|}{ DPOAE Thresholds } \\
\hline & Vehicle Condition & Treatment & 0.1903 & 0.6671 \\
\hline & E2 Condition & Treatment & 36.11 & $<0.0001$ \\
\hline Paired Synapses & & Treatment & 0.7923 & 0.3903 \\
\hline \multicolumn{5}{|l|}{ PTS Experiments } \\
\hline \multicolumn{5}{|l|}{ ABR Thresholds } \\
\hline & Baseline & Sex & 0.1007 & 0.7516 \\
\hline & & Treatment & 0.005573 & 0.9406 \\
\hline & CTS & Sex & 21.04 & $<0.0001$ \\
\hline & & Treatment & 17.15 & $<0.0001$ \\
\hline & PTS & Sex & 27.25 & $<0.0001$ \\
\hline & & Treatment & 33.55 & $<0.0001$ \\
\hline OHC Loss & & Treatment & 9.791 & 0.0019 \\
\hline Paired Synapses & & Treatment & 3.009 & 0.1033 \\
\hline \multicolumn{5}{|l|}{ TTS Experiments } \\
\hline \multicolumn{5}{|l|}{ ABR Thresholds } \\
\hline & Baseline & Treatment & 2.144 & 0.1465 \\
\hline & CTS & Treatment & 34.03 & $<0.0001$ \\
\hline & TTS & Treatment & 0.09137 & 0.7631 \\
\hline \multicolumn{5}{|l|}{ Wave-1 Amplitudes } \\
\hline & $8 \mathrm{kHz}$ & Treatment & 30.99 & $<0.0001$ \\
\hline & $16 \mathrm{kHz}$ & Treatment & 42.32 & $<0.0001$ \\
\hline & $24 \mathrm{kHz}$ & Treatment & 59.31 & $<0.0001$ \\
\hline & $32 \mathrm{kHz}$ & Treatment & 58.97 & $<0.0001$ \\
\hline OHC Loss & & Treatment & 5.517 & 0.0278 \\
\hline Paired Synapses & & Treatment & 6.705 & 0.0100 \\
\hline
\end{tabular}

\section{References}

1. World Health Organization. Deafness and Hearing Loss. Available online: https://www.who.int/news-room/fact-sheets/ detail/deafness-and-hearing-loss (accessed on 8 June 2018).

2. Haile, L.M.; Kamenov, K.; Briant, P.S.; Orji, A.U.; Steinmetz, J.D.; Abdoli, A.; Abdollahi, M.; Abu-Gharbieh, E.; Afshin, A.; Ahmed, H.; et al. Hearing loss prevalence and years lived with disability, 1990-2019: Findings from the Global Burden of Disease Study 2019. Lancet 2021, 397, 996-1009. [CrossRef]

3. Crowson, M.G.; Hertzano, R.; Tucci, D.; Neurotol, O. Emerging Therapies for Sensorineural Hearing Loss HHS Public Access Author manuscript. Otol. Neurotol. 2017, 38, 792-803. [CrossRef]

4. Ma, Y.; Wise, A.K.; Shepherd, R.K.; Richardson, R.T. New molecular therapies for the treatment of hearing loss. Pharmacol. Ther 2019, 200, 190-209. [CrossRef] 
5. Le, T.N.; Straatman, L.V.; Lea, J.; Westerberg, B. Current insights in noise-induced hearing loss: A literature review of the underlying mechanism, pathophysiology, asymmetry, and management options. J. Otolaryngol. Head Neck Surg. 2017, 46, 41. [CrossRef] [PubMed]

6. Ryan, A.F.; Kujawa, S.G.; Hammill, T.; Le Prell, C.; Kil, J. Temporary and Permanent Noise-Induced Threshold Shifts: A Review of Basic and Clinical Observations. Otol. Neurotol. 2016, 37, 271-275. [CrossRef] [PubMed]

7. Liberman, M.C.; Epstein, M.J.; Cleveland, S.S.; Wang, H.; Maison, S.F. Toward a Differential Diagnosis of Hidden Hearing Loss in Humans. PLoS ONE 2016, 11, e0162726. [CrossRef] [PubMed]

8. Liberman, M.C.; Kujawa, S.G. Cochlear synaptopathy in acquired sensorineural hearing loss: Manifestations and mechanisms. Hear. Res. 2017, 349, 138-147. [CrossRef] [PubMed]

9. Furman, A.C.; Kujawa, S.G.; Liberman, M.C. Noise-induced cochlear neuropathy is selective for fibers with low spontaneous rates. J. Neurophysiol. 2013, 110, 577-586. [CrossRef] [PubMed]

10. Shrestha, B.R.; Chia, C.; Wu, L.; Kujawa, S.G.; Liberman, M.C.; Goodrich, L.V. Sensory Neuron Diversity in the Inner Ear Is Shaped by Activity. Cell 2018, 174, 1229-1246.e17. [CrossRef] [PubMed]

11. Plack, C.J.; Barker, D.; Prendergast, G. Perceptual consequences of 'hidden' hearing loss. Trends Hear. 2014, 18, 1-11. [CrossRef]

12. Nordmann, A.S.; Bohne, B.A.; Harding, G.W. Histopathological differences between temporary and permanent threshold shift. Hear. Res. 2000, 139, 13-30. [CrossRef]

13. Ou, H.C.; Bohne, B.A.; Harding, G.W. Noise damage in the C57BL/CBA mouse cochlea. Hear. Res. 2000, 145, 111-122. [CrossRef]

14. Sha, S.H.; Taylor, R.; Forge, A.; Schacht, J. Differential vulnerability of basal and apical hair cells is based on intrinsic susceptibility to free radicals. Hear. Res. 2001, 155, 1-8. [CrossRef]

15. Shuster, B.Z.; Depireux, D.A.; Mong, J.A.; Hertzano, R. Sex Differences in Hearing: Probing the Role of Estrogen Signaling. J. Acoust. Soc. Am. 2019, 145, 3656-3663. [CrossRef]

16. Milon, B.; Mitra, S.; Song, Y.; Margulies, Z.; Casserly, R.; Drake, V.; Mong, J.A.; Depireux, D.A.; Hertzano, R. The impact of biological sex on the response to noise and otoprotective therapies against acoustic injury in mice. Biol. Sex Differ. $2018,9,12$. [CrossRef] [PubMed]

17. Rouse, S.L.; Matthews, I.R.; Li, J.; Sherr, E.H.; Chan, D.K. Integrated stress response inhibition provides sex-dependent protection against noise-induced cochlear synaptopathy. Sci. Rep. 2020, 10, 18063. [CrossRef] [PubMed]

18. Caras, M.L. Estrogenic modulation of auditory processing: A vertebrate comparison. Front. Neuroendocrinol. 2013, 34, 285-299. [CrossRef]

19. Charitidi, K.; Meltser, I.; Tahera, Y.; Canlon, B. Functional responses of estrogen receptors in the male and female auditory system. Hear. Res. 2009, 252, 71-78. [CrossRef]

20. Delhez, A.; Lefebvre, P.; Péqueux, C.; Malgrange, B.; Delacroix, L. Auditory function and dysfunction: Estrogen makes a difference. Cell. Mol. Life Sci. 2019, 77, 619-635. [CrossRef]

21. Villavisanis, D.F.; Berson, E.R.; Lauer, A.M.; Cosetti, M.K.; Schrode, K.M. Sex-based Differences in Hearing Loss: Perspectives from Non-clinical Research to Clinical Outcomess. In Otology and Neurotology; Lippincott Williams and Wilkins: Philadelphia, PA, USA, 2020; Volume 41, pp. 290-298.

22. Meltser, I.; Tahera, Y.; Simpson, E.; Hultcrantz, M.; Charitidi, K.; Gustafsson, J.A.; Canlon, B. Estrogen receptor Beta protects against acoustic trauma in mice. J. Clin. Investig. 2008, 118, 1563-1570. [CrossRef]

23. Simonoska, R.; Stenberg, A.E.; Duan, M.; Yakimchuk, K.; Fridberger, A.; Sahlin, L.; Gustafsson, J.A.; Hultcrantz, M. Inner ear pathology and loss of hearing in estrogen receptor-beta deficient mice. J. Endocrinol. 2009, 201, 397-406. [CrossRef] [PubMed]

24. McHenry, J.; Carrier, N.; Hull, E.; Kabbaj, M. Sex differences in anxiety and depression: Role of testosterone. In Frontiers in Neuroendocrinology; Academic Press: Cambridge, MA, USA, 2014; Volume 35, pp. 42-57.

25. Brinton, R.D. Minireview: Translational Animal Models of Human Menopause: Challenges and Emerging Opportunities. Endocrinology 2012, 153, 3571-3578. [CrossRef] [PubMed]

26. Komori, T. Animal models for osteoporosis. Eur. J. Pharm. 2015, 759, 287-294. [CrossRef] [PubMed]

27. Eggermont, J.J. Auditory brainstem response. In Handbook of Clinical Neurology; Elsevier B.V.: Amsterdam, The Netherlands, 2019; Volume 160, pp. 451-464.

28. Kemp, D. Otoacoustic emissions, their origin in cochlear function, and use. Br. Med. Bull. 2002, 63, 223-241. [CrossRef] [PubMed]

29. Brownell, W.E. Outer Hair Cell Electromotility and Otoacoustic Emissions. Ear Hear. 1990, 11, 82-92. [CrossRef]

30. Abdala, C.; Visser-Dumont, L. Distortion Product Otoacoustic Emissions: A Tool for Hearing Assessment and Scientific Study. Volta Rev. 2001, 103, 281-302. [PubMed]

31. Korrapati, S.; Taukulis, I.; Olszewski, R.; Pyle, M.; Gu, S.; Singh, R.; Griffiths, C.; Martin, D.; Boger, E.; Morell, R.J.; et al. Single Cell and Single Nucleus RNA-Seq Reveal Cellular Heterogeneity and Homeostatic Regulatory Networks in Adult Mouse Stria Vascularis. Front. Mol. Neurosci. 2019, 12, 316. [CrossRef] [PubMed]

32. Wangemann, P. K+ cycling and the endocochlear potential. Hear. Res. 2002, 165, 1-9. [CrossRef]

33. Ohlemiller, K.K.; Kaur, T.; Warchol, M.E.; Withnell, R.H. The endocochlear potential as an indicator of reticular lamina integrity after noise exposure in mice. Hear. Res. 2018, 361, 138-151. [CrossRef]

34. Ohlemiller, K.K. Mechanisms and genes in human strial presbycusis from animal models. Brain Res. 2009, 1277, 70-83. [CrossRef]

35. Sewell, W.F. The effects of furosemide on the endocochlear potential and auditory-nerve fiber tuning curves in cats. Hear. Res. 1984, 14, 305-314. [CrossRef] 
36. Ohlemiller, K.K.; Jones, S.M.; Johnson, K.R. Application of Mouse Models to Research in Hearing and Balance. J. Assoc. Res. Otolaryngol. 2016, 17, 493-523. [CrossRef] [PubMed]

37. Kujawa, S.G.; Liberman, M.C. Synaptopathy in the noise-exposed and aging cochlea: Primary neural degeneration in acquired sensorineural hearing loss. Hear. Res. 2015, 330, 191-199. [CrossRef] [PubMed]

38. Wang, Y.; Hirose, K.; Liberman, M.C. Dynamics of Noise-Induced Cellular Injury and Repair in the Mouse Cochlea. J. Assoc. Res. Otolaryngol. 2002, 3, 248-268. [CrossRef] [PubMed]

39. Gao, W.-Y.; Ding, D.-L.; Zheng, X.-Y.; Ruan, F.-M.; Liu, Y.-J. A comparison of changes in the stereocilia between temporary and permanent hearing losses in acoustic trauma. Hear. Res. 1992, 62, 27-41. [CrossRef]

40. Hederstierna, C.; Hultcrantz, M.; Collins, A.; Rosenhall, U. The menopause triggers hearing decline in healthy women. Hear. Res. 2010, 259, 31-35. [CrossRef]

41. Kim, S.H.; Kang, B.M.; Chae, H.D.; Kim, C.H. The Association between Serum Estradiol Level and Hearing Sensitivity in Postmenopausal Women. Obs. Gynecol. 2002, 99, 726-730.

42. Seist, R.; Tong, M.; Landegger, L.D.; Vasilijic, S.; Hyakusoku, H.; Katsumi, S.; McKenna, C.E.; Edge, A.S.B.; Stankovic, K.M. Regeneration of Cochlear Synapses by Systemic Administration of a Bisphosphonate. Front. Mol. Neurosci. 2020, 13, 87. [CrossRef]

43. Brandt, A.; Striessnig, J.; Moser, T. CaV1.3 Channels Are Essential for Development and Presynaptic Activity of Cochlear Inner Hair Cells. J. Neurosci. 2003, 23, 10832-10840. [CrossRef] [PubMed]

44. Lösel, R.M.; Falkenstein, E.; Feuring, M.; Schultz, A.; Tillmann, H.-C.; Rossol-Haseroth, K.; Wehling, M. Nongenomic Steroid Action: Controversies, Questions, and Answers. Physiol. Rev. 2003, 83, 965-1016. [CrossRef]

45. Moser, T.; Beutner, D. Kinetics of exocytosis and endocytosis at the cochlear inner hair cell afferent synapse of the mouse. Proc. Natl. Acad. Sci. USA 2000, 97, 883-888. [CrossRef] [PubMed]

46. Rutherford, M.A.; Chapochnikov, N.M.; Moser, T. Spike Encoding of Neurotransmitter Release Timing by Spiral Ganglion Neurons of the Cochlea. J. Neurosci. 2012, 32, 4773-4789. [CrossRef] [PubMed]

47. Björnström, L.; Sjöberg, M. Mechanisms of Estrogen Receptor Signaling: Convergence of Genomic and Nongenomic Actions on Target Genes. Mol. Endocrinol. 2005, 19, 833-842. [CrossRef] [PubMed]

48. Motohashi, R.; Takumida, M.; Shimizu, A.; Konomi, U.; Fujita, K.; Hirakawa, K.; Suzuki, M.; Anniko, M. Effects of age and sex on the expression of estrogen receptor $\alpha$ and $\beta$ in the mouse inner ear. Acta Oto-Laryngol. 2010, 130, 204-214. [CrossRef] [PubMed]

49. Stenberg, A.E.; Wang, H.; Sahlin, L.; Hultcrantz, M. Mapping of estrogen receptors $\alpha$ and $\beta$ in the inner ear of mouse and rat. Hear. Res. 1999, 136, 29-34. [CrossRef]

50. Saito, K.; Cui, H. Emerging Roles of Estrogen-Related Receptors in the Brain: Potential Interactions with Estrogen Signaling. Int. J. Mol. Sci. 2018, 19, 1091. [CrossRef]

51. Smith, S.B.; Lichtenhan, J.T.; Cone, B.K. Contralateral inhibition of click- and chirp-evoked human compound action potentials. Front. Neurosci. 2017, 11, 189. [CrossRef]

52. Hara, Y.; Waters, E.M.; McEwen, B.S.; Morrison, J.H. Estrogen Effects on Cognitive and Synaptic Health over the Lifecourse. Physiol. Rev. 2015, 95, 785-807. [CrossRef]

53. Hu, R.; Cai, W.; Wu, X.; Yang, Z. Astrocyte-derived estrogen enhances synapse formation and synaptic transmission between cultured neonatal rat cortical neurons. Neuroscience 2007, 144, 1229-1240. [CrossRef]

54. Lu, Y.; Sareddy, G.R.; Wang, J.; Wang, R.; Li, Y.; Dong, Y.; Zhang, Q.; Liu, J.; O'Connor, J.C.; Xu, J.; et al. Neuron-Derived Estrogen Regulates Synaptic Plasticity and Memory. J. Neurosci. 2019, 39, 2792-2809. [CrossRef]

55. Spencer-Segal, J.; Tsuda, M.; Mattei, L.; Waters, E.; Romeo, R.; Milner, T.; McEwen, B.; Ogawa, S. Estradiol acts via estrogen receptors alpha and beta on pathways important for synaptic plasticity in the mouse hippocampal formation. Neuroscience 2012, 202, 131-146. [CrossRef]

56. Hashimoto, K.; Hickman, T.T.; Suzuki, J.; Ji, L.; Kohrman, D.C.; Corfas, G.; Liberman, M.C. Protection from noise-induced cochlear synaptopathy by virally mediated overexpression of NT3. Sci. Rep. 2019, 9, 15362. [CrossRef]

57. Suzuki, J.; Corfas, G.; Liberman, M.C. Round-window delivery of neurotrophin 3 regenerates cochlear synapses after acoustic overexposure. Sci. Rep. 2016, 6, 24907. [CrossRef] [PubMed]

58. Arevalo, M.-A.; Azcoitia, I.; Garcia-Segura, L. The neuroprotective actions of oestradiol and oestrogen receptors. Nat. Rev. Neurosci. 2015, 16, 17-29. [CrossRef] [PubMed]

59. Gillies, G.E.; McArthur, S. Estrogen Actions in the Brain and the Basis for Differential Action in Men and Women: A Case for Sex-Specific Medicines. Pharm. Rev. 2010, 62, 155-198. [CrossRef] [PubMed]

60. FDing, F.; Yao, J.; Zhao, L.; Mao, Z.; Chen, S.; Brinton, R.D. Ovariectomy Induces a Shift in Fuel Availability and Metabolism in the Hippocampus of the Female Transgenic Model of Familial Alzheimer's. PLoS ONE 2013, 8, e59825.

61. Azcoitia, I.; Fernandez-Galaz, C.; Sierra, A.; Garcia-Segura, L.M. Gonadal hormones affect neuronal vulnerability to excitotoxininduced degeneration. J. Neurocytol. 1999, 28, 699-710. [CrossRef] [PubMed]

62. Kim, K.X.; Payne, S.; Yang-Hood, A.; Li, S.-Z.; Davis, B.; Carlquist, J.; V-Ghaffari, B.; Gantz, J.A.; Kallogjeri, D.; Fitzpatrick, J.A.; et al. Vesicular Glutamatergic Transmission in Noise-Induced Loss and Repair of Cochlear Ribbon Synapses. J. Neurosci. 2019, 39, 4434-4447. [CrossRef] [PubMed]

63. Puel, J.-L.; Ruel, J.; D'aldin, C.G.; Pujol, R. Excitotoxicity and repair of cochlear synapses after noise-trauma induced hearing loss. NeuroReport 1998, 9, 2109-2114. [CrossRef] [PubMed] 
64. Hu, N.; Rutherford, M.A.; Green, S.H. Protection of cochlear synapses from noise-induced excitotoxic trauma by blockade of $\mathrm{Ca}^{2+}$-permeable AMPA receptors. Proc. Natl. Acad. Sci. USA 2020, 117, 3828-3838. [CrossRef]

65. Petrone, A.B.; Gatson, J.W.; Simpkins, J.W.; Reed, M.N. Non-feminizing estrogens: A novel neuroprotective therapy. Mol. Cell. Endocrinol. 2014, 389, 40-47. [CrossRef] [PubMed]

66. Pinkerton, J.V.; Thomas, S. Use of SERMs for treatment in postmenopausal women. J. Steroid Biochem. Mol. Biol. 2014, 142, 142-154. [CrossRef] [PubMed]

67. Gillies, E.G.; Murray, E.H.; Dexter, D.; McArthur, S. Sex dimorphisms in the neuroprotective effects of estrogen in an animal model of Parkinson's disease. Pharm. Biochem. Behav. 2004, 78, 513-522. [CrossRef] [PubMed]

68. Razmara, A.; Duckles, S.P.; Krause, D.N.; Procaccio, V. Estrogen suppresses brain mitochondrial oxidative stress in female and male rats. Brain Res. 2007, 1176, 71-81. [CrossRef] [PubMed]

69. Rusa, R.; Alkayed, N.J.; Crain, B.J.; Traystman, R.J.; Kimes, A.S.; London, E.D.; Klaus, J.A.; Hurn, P.D. 17ß-Estradiol Reduces Stroke Injury in Estrogen-Deficient Female Animals. Stroke 1999, 30, 1665-1670. [CrossRef] [PubMed]

70. Toung, T.J.K.; Traystman, R.J.; Hurn, P.D. Estrogen-Mediated Neuroprotection after Experimental Stroke in Male Rats. Stroke 1998, 29, 1666-1670. [CrossRef] [PubMed]

71. McCarthy, M.M.; Arnold, A.P. Reframing sexual differentiation of the brain. Nat. Neurosci. 2011, 14, 677-683. [CrossRef] [PubMed]

72. Bhatt, I.; Phillips, S.; Richter, S.; Tucker, D.; Lundgren, K.; Morehouse, R.; Henrich, V. A polymorphism in human estrogen-related receptor beta (ESRR $\beta)$ predicts audiometric temporary threshold shift. Int. J. Audiol 2016, 55, 571-579. [CrossRef] [PubMed]

73. Nolan, L.S.; Maier, H.; Hermans-Borgmeyer, I.; Girotto, G.; Ecob, R.; Pirastu, N.; Cadge, B.A.; Hübner, C.; Gasparini, P.; Strachan, D.P.; et al. Estrogen-related receptor gamma and hearing function: Evidence of a role in humans and mice. Neurobiol. Aging 2013, 34, 2077. [CrossRef] [PubMed]

74. Schilit, S.L.; Currall, B.B.; Yao, R.; Hanscom, C.; Collins, R.L.; Pillalamarri, V.; Lee, D.-Y.; Kammin, T.; Zepeda-Mendoza, C.J.; Mononen, T.; et al. Estrogen-related receptor gamma implicated in a phenotype including hearing loss and mild developmental delay. Eur. J. Hum. Genet. 2016, 24, 1622-1626. [CrossRef]

75. Ben Saïd, M.; Ayedi, L.; Mnejja, M.; Hakim, B.; Khalfallah, A.; Charfeddine, I.; Khifagi, C.; Turki, K.; Ayadi, H.; BenZina, Z.; et al. A novel missense mutation in the ESRRB gene causes DFNB35 hearing loss in a Tunisian family. Eur. J. Med. Genet. 2011, 54, e535-e541. [CrossRef] [PubMed]

76. Adriztina, I.; Adnan, A.; Adenin, I.; Haryuna, S.H.; Sarumpaet, S. Influence of hormonal changes on audiologic examination in normal ovarian cycle females: An analytic study. Int. Arch. Otorhinolaryngol. 2016, 20, 294-299. [CrossRef] [PubMed]

77. Jian, H.; Yu, G.; Chen, G.; Lin, N.; Wang, H. Correlation between auditory-vestibular functions and estrogen levels in postmenopausal patients with Meniere's disease. J. Clin. Lab. Anal. 2019, 33, e22626. [CrossRef] [PubMed]

78. Fernandez, K.A.; Jeffers, P.W.; Lall, K.; Liberman, M.C.; Kujawa, S.G. Aging after Noise Exposure: Acceleration of Cochlear Synaptopathy in "Recovered" Ears. J. Neurosci. 2015, 35, 7509-7520. [CrossRef]

79. Wu, P.; O’Malley, J.T.; de Gruttola, V.; Liberman, M.C. Age-Related Hearing Loss Is Dominated by Damage to Inner Ear Sensory Cells, Not the Cellular Battery That Powers Them. J. Neurosci. 2020, 40, 6357-6366. [CrossRef] [PubMed]

80. Pottoo, F.H.; Bhowmik, M.; Vohora, D. Raloxifene protects against seizures and neurodegeneration in a mouse model mimicking epilepsy in postmenopausal woman. Eur. J. Pharm. Sci. 2014, 65, 167-173. [CrossRef] [PubMed]

81. Driowo, M.; Landgren, B.-M.; Stenström, B.; Diczfalusy, E. A comparison of the pharmacokinetic properties of three estradiol esters. Contraception 1980, 21, 415-424. [CrossRef]

82. Lund-Pero, M.; Jeppson, B.; Arneklo-Nobin, B.; Sjögren, H.-O.; Holmgren, K.; Pero, R.W. Non-specific steroidal esterase activity and distribution in human and other mammalian tissues. Clin. Chim. Acta 1994, 224, 9-20. [CrossRef]

83. Wangemann, P.; Itza, E.M.; Albrecht, B.; Wu, T.; Jabba, S.V.; Maganti, R.J.; Lee, J.H.; Everett, L.A.; Wall, S.M.; E Royaux, I.; et al. Loss of KCNJ10 protein expression abolishes endocochlear potential and causes deafness in Pendred syndrome mouse model. BMC Med. 2004, 2, 30. [CrossRef]

84. Wangemann, P.; Nakaya, K.; Wu, T.; Maganti, R.J.; Itza, E.M.; Sanneman, J.D.; Harbidge, D.G.; Billings, S.; Marcus, D.C. Loss of cochlear $\mathrm{HCO}_{3}{ }^{-}$secretion causes deafness via endolymphatic acidification and inhibition of $\mathrm{Ca}^{2+}$ reabsorption in a Pendred syndrome mouse model. Am. J. Physiol.-Ren. Physiol. 2007, 292, F1345-F1353. [CrossRef]

85. Morell, R.J.; Olszewski, R.; Tona, R.; Leitess, S.; Wafa, T.; Taukulis, I.; Schultz, J.M.; Thomason, E.J.; Richards, K.; Whitley, B.N.; et al. Noncoding Microdeletion in Mouse Hgf Disrupts Neural Crest Migration into the Stria Vascularis, Reduces the Endocochlear Potential, and Suggests the Neuropathology for Human Nonsyndromic Deafness DFNB39. J. Neurosci. 2020, 40, $2976-2992$. [CrossRef] [PubMed]

86. Ohlemiller, K.K.; Dahl, A.R.; Gagnon, P.M. Divergent Aging Characteristics in CBA/J and CBA/CaJ Mouse Cochleae. J. Assoc. Res. Otolaryngol. 2010, 11, 605-623. [CrossRef] [PubMed]

87. Mouse Cochlear Dissection. Available online: https://vimeo.com/144531710 (accessed on 29 September 2020). 